\title{
Supersonic/Hypersonic Laminar Heating Correlations for Rectangular and Impact-Induced Open and Closed Cavities
}

\author{
Joel L. Everhart* \\ NASA Langley Research Center, Hampton, VA, 23681
}

\begin{abstract}
Impact and debris damage to the Space Shuttle Orbiter Thermal Protection System tiles is a random phenomenon, occuring at random locations on the vehicle surface, resulting in random geometrical shapes that are exposed to a definable range of surface flow conditions. In response to the $\mathbf{2 0 0 3}$ Final Report of the Columbia Accident Investigation Board, wind tunnel aeroheating experiments approximating a wide range of possible damage scenarios covering both open and closed cavity flow conditions were systematically tested in hypersonic ground based facitilies. These data were analyzed and engineering assessment tools for damage-induced fully-laminar heating were developed and exercised on orbit. These tools provide bounding approximations for the damaged-surface heating environment. This paper presents a further analysis of the baseline, zero-pressure-gradient, idealized, rectangular-geometry cavity heating data, yielding new laminar correlations for the floor-averaged heating, peak cavity endwall heating, and the downstream decay rate. Correlation parameters are derived in terms of cavity geometry and local flow conditions. Prediction Limit Uncertainty values are provided at the $95 \%, 99 \%$ and $99.9 \%$ levels of significance. Non-baseline conditions, including non-rectangular geometries and flows with known pressure gradients, are used to assess the range of applicability of the new correlations. All data variations fall within the $\mathbf{9 9 \%}$ Prediction Limit Uncertainty bounds. Importantly, both open-flow and closed-flow cavity heating are combined into a single-curve parameterization of the heating predictions, and provide a concise mathematical model of the laminar cavity heating flow field with known uncertainty.
\end{abstract}

\section{Nomenclature}

$\mathrm{Cp} \quad$ pressure coefficient

$\mathrm{h} \quad$ heat transfer coefficient, $\mathrm{h}=\mathrm{q} /\left(\mathrm{H}_{\mathrm{aw}}-\mathrm{H}_{\mathrm{w}}\right),\left(\mathrm{lbm} / \mathrm{ft}^{2} / \mathrm{s}\right)$

$\mathrm{H} \quad$ enthalpy (btu/lbm)

L, W, H cavity length, width, and depth (in)

M Mach number

$\mathrm{M}_{\mathrm{e}} \quad$ boundary layer edge Mach number at the cavity entrance

$\mathrm{p} \quad$ pressure (psi)

$\mathrm{R}^{2} \quad$ Linear Correlation Coefficient

$\mathrm{Re} \quad$ unit Reynolds number ( $1 / \mathrm{ft})$

$\operatorname{Re}_{\theta} \quad$ momentum thickness Reynolds number

$\mathrm{x} \quad$ axial distance from model leading edge (in)

y spanwise distance from model centerline (in)

$\mathrm{z} \quad$ distance normal to $\mathrm{x}$-y plane (in)

$\alpha \quad$ angle-of-attack (deg)

$\gamma \quad$ ratio of specific heats

$\delta \quad$ boundary layer thickness (in)

$\theta \quad$ boundary layer momentum thickness (in)

Acronymns

BF Bump Factor

${ }^{*}$ Senior Research Engineer, Aerothermodynamics Branch, and AIAA Associate Fellow. 


$\begin{array}{ll}\text { BF }_{\mathrm{AVG}} & \text { Average Bump Factor on the cavity floor } \\ \mathrm{BF}_{\mathrm{MAX}} & \text { maximum Bump Factor on the cavity end wall } \\ \text { CAIB } & \text { Columbia Accident Investigation Board } \\ \text { LCL } & \text { Lower Confidence Limit } \\ \text { LPL } & \text { Lower Prediction Limit } \\ \text { RTF } & \text { Return-to-Flight } \\ \text { TGP } & \text { thermographic phosphor } \\ \text { TPS } & \text { thermal protection system } \\ \text { UCL } & \text { Upper Confidence Limit } \\ \text { UPL } & \text { Upper Prediction Limit } \\ \text { Subscripts } & \\ \text { AVG } & \text { average } \\ \text { FR } & \text { stagnation point conditions from Fay-Riddell calculation for a hemisphere } \\ \text { init } & \text { initial } \\ \text { P } & \text { preliminary } \\ \infty & \text { freestream static conditions }\end{array}$

\section{Introduction}

The August 2003 Final Report of the Columbia Accident Investigation Board (CAIB) identified "a breach in the Thermal Protection System of the leading edge of the left wing, caused by a piece of insulating foam ..." as the probable event resulting in the loss of the Space Shuttle Columbia during flight STS-107 on February 1, 2003. Since laminar boundary layer flow exists over much of the Orbiter re-entry trajectory and since the CAIB analysis indicated smaller safety margins than desired over certain regions of the vehicle, improved damage assessment models were needed to augment the existing turbulent modeling methods. Therefore, the CAIB further recommended that NASA "Develop, validate, and maintain physics-based computer models to evaluate Thermal Protection System damage from debris impacts." Developing a rational, validated, geometry description of a randomly-occuring, impact-induced cavity became a major implemation challenge for Shuttle Return To Flight Program (RTF).

An examination of the literature revealed that much general information was available on cavity flow physics and heating; however, specific information required to address laminar issues associated with Orbiter damage was very sparse. Fletcher, et al. ${ }^{1}$ and Nestler ${ }^{2}$ published excellent survey papers that capture much of the pertinent published research. Theoretically, none of the simple models they cited adequately capture the three-dimensional cavity physics because they miss the vortex development on the cavity top sidewall corners, on the floor of the cavity, and downstream of the cavity at the outside edges, as observed in the global surface heating distributions presented herein. Recent numerical studies conducted for the CAIB and the Shuttle RTF program demonstrate the difficulty in accurately modeling cavity flows ${ }^{3,4}$. Experimentally, laminar two-dimensional flows were addressed by Galenter $^{5}$ and Nestler ${ }^{6}$; laminar axisymmetric flows were addressed by Nestler ${ }^{7}$, Nicoll ${ }^{8,9}$, and Wyborny, et al. ${ }^{10}$; and, laminar three-dimensional flows were examined by Cheatwood, et al. ${ }^{11}, \mathrm{Hahn}^{12}$, and Nestler ${ }^{13}$. In general, these early heating measurements were obtained with sparsely-spaced discrete sensors that miss much of the threedimensional nature of the surface heating profile, and in many cases the important peak heating value.

This lack of information led to extensive wind tunnel experiments by Everhart, et al. ${ }^{14,15,16,17}$ on a multitude of idealized cavity geometries to establish the effects of length, width, depth, entry/exit/sidewall angles, orientation, surface curvature, and the fluid dynamic effects of Mach number, Reynolds number, and boundary layer thickness on the aeroheating changes to the vehicle surface. These measurements are greatly enhanced because they were made using global phosphor thermography methods. Preliminary analysis of these data enabled the development of bounding-value assessment tools ${ }^{18}$ to model the damaged-surface heating augmentation. Because a bounding analysis was used, the tools are discontinuous in application and their uncertainty estimates are overly conservative.

The purpose of this paper is to present a more refined aeroheating analysis of the laminar-entry/laminar-exit cavity flow field developed using only the rectangular-cavity database acquired for the Shuttle Return-To-Flight Program. Empirical correlation curves will be established for the average heating on the cavity floor and for the maximum heating on the cavity endwall. Uncertainty Limits will be established at the $95 \%, 99 \%$, and $99.9 \%$ confidence levels on the curve coefficients, and corresponding Prediction Limits will be developed to provide the regions of applicablity about the curves. After establishing these correlations, cavity-heating data from the same test series covering a wide range of the geometry variations simulating the effects of randomness will be used to 
establish the generality of the rectangular-geometry heating model. A comparison of the empirical model with computational simulations is also provided. Additionally, the downstream heating decay rate will be established for both open and closed cavities. The combination of these elements provides the necessary components to define a heating model for impact-induced cavities in a laminar-entry/laminar-exit boundary layer flow field.

\section{Supersonic/Hypersonic Cavity Flow Physics}

The literature survey provides the following overview of cavity flow physics. Typically, length-to-depth ratio $(\mathrm{L} / \mathrm{H})$ is used to distinguish between and classify different cavity flow regimes ${ }^{19,20}$, as depicted in Figure 1 . The impact of cavity depth ratio, $\mathrm{H} / \delta$, is typically assessed via the use of "thin" and "thick" boundary layers. Very short or deep cavities with $\mathrm{L} / \mathrm{H}<1$ are known as gaps. In this case, the main stream flows over the gap and its shearing causes the formation of a column of counter-rotating vortices within the gap, numbering approximately $\mathrm{H} / \mathrm{L}$. Alternating hot spots are developed on the sidewalls when the vortices directionally align.

Two stable flow conditions exist for cavities with length $\mathrm{L} / \mathrm{H}>1$. The first is a short cavity in the length range $1 \leq \mathrm{L} / \mathrm{H} \leq 10$, defined as an open cavity. The mainstream flow does not enter the cavity directly, though there may be some mass interchange with the low-energy vortical flow inside the cavity. Physically, the short cavity has insufficient length to support the required entry and exit turning angles, therefore it skims the cavity. The pressure in the cavity is typically above the ambient and climbs to a peak at the downstream lip. The heating drops to values significantly below the undisturbed value and rises slowly to a peak value on the downstream lip. The other stable solution is a long cavity, also known as a closed cavity, with length $\mathrm{L} / \mathrm{H} \geq 14$. In this case, three distinct flows may develop if the cavity is long enough. First, the upstream flow is now able to turn into the cavity and impinge on the floor, creating an aft-facing-step flow field. Next, a boundary layer on the floor may develop and recover to the ambient level outside the cavity. Finally, as the flow approaches the endwall it will turn outward and create a threedimensional forward-facing-step flow field. For long, deep cavities, the pressure gradients may be severe where the flow turns and strong expansion and shock waves will be generated. Viscous shearing generated by this flow turning will augment the heating to levels significantly higher than the ambient levels on both the cavity floor and the endwall. The pressure in these long cavities will decrease below the ambient and steadily increase downstream, reaching large values of over-pressure behind the shocks. Vortices will develop on the cavity sidewalls as the flow expands around the corner into the cavity and on the floor after flow impingement, further augmenting the heating, which may extend laterally around the cavity in the most severe cases. These vortices will interact with the cavity end wall and spill into the downstream region. Given laminar inflow, analysis of the heating profiles indicates that most any type of outflow may occur, depending on the cavity and its environmental state. The in-cavity flow may remain laminar, become transitional, or transition to fully turbulent flow; the downstream possibilities are equally varied and are currently the subject of extensive analysis and testing in support of Shuttle RTF ${ }^{21}$.

Transitional cavities occurring in the range $10 \leq \mathrm{L} / \mathrm{H} \leq 14$ are unsteady as the flow alternates between the two bounding conditions. Oil flow visualizations of both open and closed conditions occurring in the same cavity model have been presented by Stallings, et. al. ${ }^{22}$ Transitional cavities have been avoided where possible in the present tests because of the instrumentation complexity and the additional data analysis challenges.

The boundaries between the different cavity flow regimes are nominal, at best. For example, different researchers have measured $\mathrm{L} / \mathrm{H}$ values ranging from 9 to 11 as the upper limit for open cavities and from 12 to 15 as the lower limit for closed cavity flow. These limits should therefore be taken only as a guide. Also, it is important to note that most of the reported cavity data were acquired in air $(\gamma=1.4)$ with some in helium $(\gamma=1.67)$. Since turning angle is a function of both Mach number and $\gamma$, it is conceivable that the open/closed cavity boundaries will vary during re-entry as vehicle boundary layer edge conditions change. At present, experimental data are insufficient to estimate the strength of this effect on the aeroheating.

\section{Analysis Data Sources}

Heating data used in the analysis were acquired in the NASA Langley 20-Inch Mach 6 and 31-Inch Mach 10 Tunnels $^{23}$ in air using the two-color phosphor thermography method ${ }^{24}$. A brief overview of the four correlation data sets and their sources is presented here. Since the tests were conducted sequentially over a 3-year period, each test series builds on and incorporates knowledge gained from preceding experiments. Thus, significant differences exist in how each was conducted, adding increased credibility to the derived uncertainty estimates. These differences will be highlighted here and in the Experimental Methods section. Figure 2 shows a simple sketch of the model coordinate system. The analysis data sets are:

Test 6888 (T6888) conducted in the 20-Inch Mach 6 Tunnel. This test was the primary database experiment used to develop the Cavity Heating Tool in support of the Shuttle Return-To-Flight Program ${ }^{18}$. These data included a 
large range of non-dimensional baseline (rectangular geometry) cavity parameters, including length $(\mathrm{L} / \mathrm{H})$, width $(\mathrm{W} / \mathrm{H})$, and depth $(\mathrm{H} / \delta)$. Also in these data were wide ranging geometry excursions designed to examine the heating effects due to randomness in the damage geometry, including symmetrical planform, profile, and cross-section variations. The impact of asymmetrical geometry varitions included cavities whose major axis was misaligned with the main flow and cavities with longitudinal depth variations. Laminar and turbulent flow conditions entering the cavity were acquired over a wide range of flow conditions. The data were acquired on a flat, near-zero-gradient pressure surface using cast ceramic cavity geometries. Post-test analysis of these data revealed that significant reductions in data uncertainty could be achieved by testing in the higher temperature Mach 10 facility. Additionally, global imaging of the region around and downstream of the cavity was desired to assess the extent of its disturbance field and to determine the heating recovery rate to ambient conditions. This requirement had the effect of spreading the coverage area of each camera pixel, increasing pixelation error in the near-field of the cavity. Subsequent experiments concentrated the measurements on the cavity near field to enhance flow-feature detection, particularly in the corners and at the edges of the cavity. This experiment is reported in detail in Ref. 16.

Test 404 (T404) conducted in the 31-Inch Mach 10 Tunnel. The emphasis of this test was shallower, smaller cavities than were acheivable during T6888. It was conducted as a rapid-response investigation immediately prior to and during the launch of STS-114 to address potential deficiencies in the existing cavity heating database. All geometries were rectangular, baseline configurations that were laser-ablated into a flat, ceramic, near-zero-gradient pressure surface. Because of the time constraints imposed by the impending launch, four cavities installed spanwise at constant longitudinal station were tested on each of the two models. For the first model, this provided a cavity depth excursion with constant cavity length, while for the second model it provided a cavity length excursion at constant depth. Analysis of the data for the outboard cavities revealed a spanwise-gradient effect on the downstream flow field; however, this effect was negligible on the cavity near field. Details of the experiment are in Ref. 17.

Test 406 (T406) conducted in the 31-Inch Mach 10 Tunnel. This test was designed to evaluate the impact of a known, controlled pressure gradient on the local heating of the baseline rectangular geometry. Two test-surface contours were provided, including an expansion-gradient surface and a zero-gradient surface for comparison. Single short and long cavities were machined into the ceramic model on its centerline, providing sharp, high-quality cavity configurations. These data are reported in detail in Ref. 14.

Test 423 (T423) conducted in the 31-Inch Mach 10 Tunnel. This test was designed to provide a direct comparison between a real, impact-induced geometry and the corresponding idealized geometry used for tool development and damage assessment. Cavities used in this experiment were cast into the ceramic model because of the ragged, non-uniform surfaces in the impact cavities. These data are reported in detail in Ref. 25. The data were also acquired on a flat, zero-gradient pressure surface; only idealized geometries are used in this analysis.

\section{Experimental Methods}

This section presents the experimental methods, beginning with a description of the test facilities. This is followed by a description of the model fabrication process, a discussion of the phosphor coating used for making the heating measurements, and the model mounting. An overview of the phosphor data system used to acquire the global heating measurements is presented.

\section{A. Facilities}

Two conventional wind tunnel facilities at the NASA Langley Research Center were used to develop the cavity heating database. The 20-Inch Mach 6 Tunnel was used to acquire data denoted as T6888 and the 31-Inch Mach 10 Tunnel was used to acquire data denoted T404, T406, and T423. They are described detail in Micol ${ }^{23}$. Flow properties for each facility were determined using the GASPROPS code developed by Hollis ${ }^{26}$.

\section{B. Models}

Ceramic casting methods were used to fabricate approximately 100 cavity models; representative models are presented in Figure 3 and Figure 4. The general manufacturing process for ceramic test articles is described in Buck, et al. ${ }^{27}$, while process modifications for these experiments are described in Buck, et al. ${ }^{28}$.

Cavity insert models developed to support T6888 are discussed in Ref. 16. These 4-inch wide by 18 -inch long inserts were installed at station $\mathrm{x}=7.5$ inches in a 10 -inch wide by 28 -inch long steel flat-plate model having a blunted leading edge with a radius of 0.125 inches. As presented in Ref. 15, the blunt nose model provides edge Mach numbers of approximately 2.9 to 3 at zero incidence as required to match the flight surface conditions. Models manufactured for T404, T406, and T423 eliminated step-gap sealing issues of previous tests by casting the entire test plate surface as a single 10 -inch-wide by 20 -inch-long ceramic piece. A 0.125 -inch radius nose was also used with 
these models. After fabrication, the models were coated with a nominal $27 \mu \mathrm{m}$ mixture of phosphors suspended in a silica-based colloidal binder ${ }^{29}$ and sent to quality assurance for measurement and application of small circular locating markers, known as fiducial marks.

\section{Cavity Designs and Test Conditions}

Impact-induced cavities must be geometrically and fluid-dynamically scaled for damage assessment modelling. For the Shuttle Orbiter, a maximum cavity depth constraint can be established based on the nominal three-inch thickness of the thermal protection system tiles; damage greater than this depth constitutes a breach of the aluminum substructure. Because of the launch configuration, impact damage on the forward portion of the vehicle is likely to be deep and short, in contrast to long, shallow grazing damage that is likely on the aft portion of the vehicle. Parametric variations used to establish the cavity heating database were guided by these considerations.

Typical surface flow conditions for the windward surface of the Shuttle Orbiter were obtained from Campbell, et al. ${ }^{30}$ to establish the parameter variations at the cavity entrance, $\left(\mathrm{M}_{\mathrm{e}}, \mathrm{Re}_{\theta}, \delta\right)_{\text {Flight }}$. Centerline test article surface conditions were determined for both the Mach 6 and Mach 10 Tunnel freestream conditions from two-dimensional centerline contour simulations of the baseline geometry using the LAURA code ${ }^{31,32}$. The range of the computationally-determined $\left(\mathrm{M}_{\mathrm{e}}, \mathrm{Re}_{\theta}\right)_{\text {Tunnel }}$ conditions were matched to flight. The boundary layer thickness ratio $\left(\delta_{\text {Tunnel }} \delta_{\text {Flight }}\right)$ was used to scale flight damage scenarios to tunnel scale. Cavity conditions $\left(\mathrm{M}_{e}, \mathrm{Re}_{\theta}, \delta\right)_{\text {Tunnel }}$ were taken from the computational solutions at the cavity entrance. Cavity entrance was at $\mathrm{x}=8$ inches to place the cavity in a region of nearly constant, almost zero pressure gradient. This forward placement of the cavity helps minimize the effects of spanwise gradients, which increase for aft locations on the model as the side-edge vortices develop toward the plate centerline. Further details of the scaling process may be found in publications by Everhart, et. al. ${ }^{14,15,16,17,25}$

Two different classes of cavities were considered: (1) baseline geometries with flat bottoms and rectangular planforms and cross sections, and (2) non-rectangular cavities with geometry variations designed to independently examine the anticipated random effects due to an impact. Within each class, both open and closed cavities were considered. The baseline geometries were easy to define and were the primary geometry used by Anderson, et al. ${ }^{18}$ to develop the Cavity Heating Tool. This simple geometry could be distinguished according to $(\mathrm{H} / \delta, \mathrm{W} / \mathrm{H}, \mathrm{L} / \mathrm{H})$. Non-rectangular geometry excursions significantly increased the geometric complexity and included symmetrical variations in planform, profile, and cross-section. Non-rectangular asymmetrical geometry excursions included effects such as rotation, different entry and exit endwall angles, and depth changes in the profile. Specifics of the cavities and their designs are included in the database publications by Everhart, et al. ${ }^{14,15,16,17,25}$

\section{Phosphor Thermography Technique}

Global surface heating distributions were calculated using the two-color, relative-intensity, phosphorthermography aeroheating measurement method and associated $\operatorname{codes}^{24}$. This is the standard method for obtaining aeroheating data in NASA Langley's hypersonic wind tunnels, and it can be used to identify the surface heating effects of complex three-dimensional flow phenomena, which are difficult to examine using conventional discretesensor methods. With this method, ceramic wind tunnel models are coated with phosphor crystals that fluoresce in the red and green regions of the visible light spectrum when illuminated by ultraviolet (UV) light. The phosphorcoated model is exposed to the heated flow during a wind tunnel run, and the resulting changes in fluorescence intensity of the model are recorded and digitized. The surface temperature distributions are determined from the fluorescence intensities through prior calibrations and analyzed using the IHEAT code, and they may be mapped onto a 3-dimensional CAD representation of the test article using the MAP3D code.

\section{E. Data Reduction}

Global mappings of the surface temperature obtained with the phosphor thermography system were reduced to surface heating distributions using the IHEAT ${ }^{24}$ data reduction software. This is done by applying one-dimensional, semi-infinite-solid heat conduction theory assuming a constant heat-transfer coefficient, and by making empirical corrections to account for temperature changes in model substrate thermal properties. The results are presented in terms of a non-dimensional heat transfer coefficient ratio, $h / h_{\mathrm{FR}}$, where $\mathrm{h}_{\mathrm{FR}}$ is the theoretical heating computed with the Fay-Riddel $l^{33}$ theory. For these experiments, $\mathrm{h}_{\mathrm{FR}}$ was computed using a 0.125 -inch radius sphere (the test model nose radius) and a reference stagnation temperature of $540^{\circ} \mathrm{R}$. Image and linecut data were converted to a cavitybased reference system by translating the origin to the leading edge center of each cavity. The data were then scaled using the cavity depth and the boundary layer thickness at the cavity leading edge to yield a scaled-geometry cavity of depth $H / \delta$, width $W / H$, and length $L / H$. 
The impact of the cavity on the local undisturbed environment was assessed by converting the local heating data to heating augmentation or bump factor (BF) format by normalizing the measured $h_{\text {local }} / h_{F R}$ by an averaged reference-location heating $h_{A V G} / h_{F R}$, yielding $B F=h_{\text {local }} / h_{A V G}$. For analysis consistency and to avoid a bias in the reference-area averaging caused by an expansion-induced heating peak upstream of the cavity leading edge, $h_{A V G} / h_{F R}$ is computed ahead of each cavity over the length $-3 \leq x / H \leq-1$. This averaging-region definition ensured that a consistent reference location was used when the data were converted to scaled, cavity space. In this format, $B F=1$ becomes the nominal, fully-developed, undisturbed condition for a flat plate. Two metrics, $B F_{A V G}$ and $B F_{M A X}$, are used to characterize the cavity heating. $B F_{A V G}$ was determined by averaging all imaged data inside the entire cavity for T6888. Only a small number of non-floor pixels were present because the camera imaging was such that the upstream endwall was not visible and only 2-3 pixels were visible in any longitudinal linecut on the downstream cavity endwall. Likewise, only one of the sidewalls was imaged and, typically, only 1-2 pixels were visible in any spanwise linecut. This area averaging greatly reduced noise in the data caused by the low temperatures experienced on the cavity floor for T6888. $B F_{A V G}$ was determined using only the centerline distribution on the cavity floor between $0.15 \leq x / L \leq 0.85$ for $\mathrm{T} 404, \mathrm{~T} 406$, and $\mathrm{T} 423 . B F_{M A X}$ was determined as the maximum value downstream of the cavity endwall. For T6888, off-centerline maximum values were considered; however, only centerline values were considered for T404, T406, and T423.

\section{Representative Test Data and Parameter Space}

Representative data taken from T6888 in bump factor format are presented here to provide an overview of the cavity heating database and to demonstrate the flow physics considered for laminar-entry/laminar-exit conditions. While laminar-entry flow can be prescribed, laminar-exit flow from the cavity can not be ensured - the cavity disturbance may act as a trip. For the final analysis, all of the data were closely screened to ensure the existence of laminar-exit conditions using both laminar and tripped-turbulent measurements made on baseline, no-cavity models to establish the respective entry/exit heating levels (see Ref. 16). Transitional flow exiting a cavity will increase and approach the turbulent level in the downstream farfield. Both transitional and fully-developed turbulent heating levels were observed within the cavities for select laminar-entry test conditions. Even though the screening process will exclude non-laminar exit flows, this screening does not preclude transition to turbulence further downstream in the farfield. Criteria for transition to turbulence due to a cavity are discussed in Horvath, et. al. ${ }^{34}$.

An example showing closed-cavity length $(L / H)$ effects on heating augmentation for laminar entry conditions is presented in the heating images shown in Figure $5 \mathrm{a}$ for $\mathrm{M}_{\mathrm{e}}=2.25, \mathrm{Re}_{\theta}=300$, and $\mathrm{H} / \delta \approx 1.35$. The corresponding cavity centerline heating distributions are presented in Figure 5b. Here, $L / H$ is systematically increased from 15.6 to 34.0. For the case where $\mathrm{L} / \mathrm{H}=15.6$ just exceeds the classical lower-limit definition for closed flow, the cold floor is dominant with a hot endwall; only small effects are seen downstream, implying minimal disturbance to the surrounding flow. For $\mathrm{L} / \mathrm{H}=20.8$, the cold floor has barely changed based on the centerline heating profiles, the endwall is hotter, the cavity wake is pronounced, and the end-wall shock/expansion system causes the flow to balloon outward and increase the heating around the side of the cavity. For $\mathrm{L} / \mathrm{H}=26.5$ and $\mathrm{L} / \mathrm{H}=34.0$, fully-developed flow at no-cavity laminar heating levels are observed on the cavity floor, large increases in the endwall occur, and the cavity-induced heating in the downstream wake is at the turbulent heating level.

The impact of planform-induced changes in open-cavity $(L / H=8)$ heating augmentation for laminar entry conditions is presented in the images in Figure $6 \mathrm{a}$ for $\mathrm{M}_{\mathrm{e}}=2.91, \mathrm{Re}_{\theta}=300$, and $\mathrm{H} / \delta=2$. The corresponding centerline distribuions are presented in Figure 6b. Diamond, circular, and square planforms show virutally no heating augmentation differences in either the images or the linecuts. Each has a cold floor, a similar hot downstream endwall, and a minimal and very rapidly decaying wake. The linecuts support the observation that the flow skips the cavity as would be expected for open flow physics.

The impact of planform-induced changes on closed-cavity $(L / H=23)$ heating are presented in Figure 7 for $\mathrm{M}_{\mathrm{e}}=2.91, \mathrm{Re}_{\theta}=300$, and $\mathrm{H} / \delta=1.35$. Relative to the Shuttle Orbiter and recalling that the TPS tiles are $\sim 3$ inches thick, these are deep cavities. The planform effects shown for the closed flow cavites have similar heating structure to the open flow cavities. However, because the flow can now actually bend into the cavity and impinge on the floor, increased heating interactions will typically occur. The longer sidewalls allow increased development and rollup of the edge vortices and this is observed in the wake. Even more adverse flow conditions will lead to increased vortex strengths, resulting in stronger interactions with the cavity downstream corners that will further enhance the possibility of boundary layer transition, resulting in increased heating.

Bump factor images and centerline heating distributions showing the effect of longitudinal changes in the cavity depth are presented in Figure 8 for $\mathrm{M}_{\mathrm{e}}=2.2$. The specific effect simulated is known as slumping and it occurs when elevated heating on the downstream endwall and floor causes the tile to collapse into itself, generating a deeper 
depth $\left(\mathrm{H}_{2}\right)$ in this region. Here, as $\mathrm{Re}_{\theta}$ increases, the decreasing boundary layer thickness yields increasing $\mathrm{H} / \delta$. These three examples demonstrate how significantly the cavity flow field can change through a re-entry trajectory.

The image and linecut data presented here represent a subset of the entire database. Using $\mathrm{BF}_{\mathrm{AVG}}$ as the metric, the available parameter space is presented in Figure 9 and the parameter ranges are summarized in Table 1.

\section{Bump Factor Correlation Parameters for Rectangular Cavities}

Figure 9 graphically documents that $\mathrm{BF}_{\mathrm{AVG}}$ does not correlate with any of the primary test parameters (e.g. $\mathrm{M}_{\mathrm{e}}$, $\mathrm{Re}_{\theta}, \mathrm{Re}_{\theta} / \mathrm{M}_{\mathrm{e}}, \mathrm{L} / \mathrm{H}, \mathrm{H} / \delta, \mathrm{L} / \delta$ ). Also, no adequate correlations of the heating augmentation metrics were identified in the literature. The first of the next two sub-sections develops preliminary correlation parameters for $\mathrm{BF}_{\mathrm{AVG}}$ and $\mathrm{BF}_{\mathrm{MAX}}$ using the baseline Mach 6 dataset, demonstrating a consistent and regular trending with variations at a prescribed cavity length $(\mathrm{L} / \mathrm{H})$. Then, final correlation parameters that collapse these trends are derived and presented.

\section{A. Preliminary Correlation Parameters}

Several different scaling concepts that feed into the development process can be obtained from the literature. First, as presented in $\mathrm{Hahn}^{12}$, Dewey ${ }^{35}$ introduced the "proper" distance variable, $\xi$, to relate the velocity ratio $\mathrm{u} * / \mathrm{u}_{\mathrm{e}}$ in a shear layer behind a hypersonic blunt body to the separation distance, where $\mathrm{u} *$ is the velocity along the dividing streamline. The distance variable was given as

$$
\xi=\left(\frac{x}{\theta}\right)^{2} \frac{1}{\operatorname{Re}_{x}}=\left(\frac{x}{H} \frac{H}{\delta} \frac{\delta}{\theta}\right) \frac{1}{\operatorname{Re}_{\theta}}
$$

Hahn used the $\xi$ variable only as a correlation parameter for his shear layer measurements. He plotted heating distributions as $\mathrm{BF}$ versus $\mathrm{x} / \mathrm{H}$, and normalized, integrated heating $\left(\mathrm{BF}_{\mathrm{AVG}}\right)$ versus cavity depth, $\delta / \mathrm{H}$. From classical boundary layer theory, $\delta / \theta$ is approximately constant for fully developed flow. Because the cavity entry Mach number at the boundary layer edge varies in the present work and because some influence was observed during the analysis, it is assumed here that the $\delta / \theta$ is also a function of $M_{e}$. Then, the distance variable is proportional to

$$
\xi \propto M_{e}{ }^{\sigma} \operatorname{Re}_{\theta}^{\tau}\left(\frac{x}{\delta}\right)
$$

Writing Eq. (2) in terms of cavity length, the preliminary cavity-length scaling variable is presented as

$$
X_{P}=M_{e}^{\sigma} \operatorname{Re}_{\theta}^{\tau}\left(\frac{L}{\delta}\right)
$$

The next concept is obtained from $\mathrm{Lamb}^{36}$ who was able to correlate convective heat transfer measurements for open cavities in laminar supersonic flow with cavity length $(\mathrm{L} / \delta)$ using the parameter

$$
Y_{P}=\left(\frac{H}{\delta}\right)^{\alpha} B F
$$

where $\alpha=0.3$ was specified. For this study, the values of the powers $\sigma$, $\tau$, and $\alpha$ in $X_{P}$ and $Y_{P}$ were determined during the correlation analysis, as discussed below.

$\mathrm{Nicol}^{9}$ recognized a distinctive power law variation in the heating of several different aspects of laminar hypersonic cavities. By analyzing experimental data he was able to suggest an inverse power law variation of heating with length along the cavity floor for laminar hypersonic flow. He further postulated that near the reattachment shoulder the variation was closer to the inverse half power variation typical of a boundary-layer type growth. Applying the power law concept and the above definitions of $X_{P}$ and $Y_{P}$ to the $66888 \mathrm{BF}_{\mathrm{AVG}}$ and $\mathrm{BF}_{\mathrm{MAX}}$ data provides the results shown in Figure 10 and Figure 11, respectively. Open symbols represent open (short) cavities 
and the closed symbols represent closed (long) cavities, while the different symbol shapes represent cavities of different lengths. The correlation parameter powers $\sigma$, $\tau$, and $\alpha$ were iteratively determined using the curve fitting routines in Microsoft Excel to minimize the Linear Correlation Coefficient, $\mathrm{R}^{2}$, of a power law curve fit through the data. For $\mathrm{BF}_{\mathrm{AVG}}$, they are $\sigma=0$ and $\tau=0.1$ in $X_{P}$ and $\alpha=3$ in $Y_{P}$; for $\mathrm{BF}_{\mathrm{MAX}}$, they are $\sigma=0.2$ and $\tau=0.05$ in $X_{P}$ and $\alpha=3.3$ in $Y_{P}$. Significant correlation is provided with this transformation as evidenced by the systematic and consistent variation with cavity length $(\mathrm{L} / \mathrm{H})$ from 7.2 to 30 , ie. across the full range of open to very long closed cavities. This consistency offers the possibility of further simplification.

\section{B. Final Correlation Parameters}

$\mathrm{Lamb}^{37}$ argued that the increased complexity of turbulent flow required the addition of the scaling factor

$$
S=\frac{L H}{L+H}=\frac{L}{1+(L / H)} \sim \frac{\text { cross-sectional area of cavity vortex }}{\text { total perimeter of cavity vortex }}
$$

as a multiplier on $(\mathrm{L} / \delta)$ for open-cavity endwall heating correlations. The scaling factor accounts for the increase in maximum convective heating caused by increased curvature of the flow. This increase in curvature is reflected in the cavity vortex "in a manner analogous to the hydraulic diameter". While the current analysis is focused on fullylaminar flow over and in open and closed cavities and while the actual physical justification of the scaling factor has never been established, including $(1+\mathrm{L} / \mathrm{H})^{\beta}$ does collapse the data. The final, revised transformation variables are

$$
\begin{aligned}
& X=\ln \left[M_{e}{ }^{\sigma} \operatorname{Re}_{\theta}^{\tau}\left(\frac{L}{\delta}\right)\right] \\
& Y=\ln \left[\left(\frac{H}{\delta}\right)^{\alpha}\left(1+\frac{L}{H}\right)^{\beta} B F\right]
\end{aligned}
$$

Applying these transformations to the $\mathrm{T} 6888 \mathrm{BF}_{\mathrm{AVG}}$ and $\mathrm{BF}_{\mathrm{MAX}}$ yields the correlations shown in Figure 12 and Figure 13, respectively. Final values for $\sigma, \tau, \alpha$, and $\beta$ are presented in Table 2 . They were, again, iteratively determined using the power-law curve fitting routines in Microsoft Excel to minimize the $\mathrm{R}^{2}$.

\section{Bump Factor Correlation Curves for Rectangular Cavities}

The correlation parameters for $\mathrm{BF}_{\mathrm{AVG}}$ and $\mathrm{BF}_{\mathrm{MAX}}$ were developed in Section VI using the baseline, rectangular cavity data from T6888. Values of these correlation parameters were next computed for all of the baseline, rectangular cavity data obtained for T6888, T404, T406, and T423. These parameters were then input to the commercially-available SYSTAT TableCurve $2 D$ program to establish the mathematical relationships for the heating variations. The linear (in transformed log-log space) correlation curve

$$
Y=a+b X
$$

was established as the proper functional representation, and the coefficients $a$ and $b$ were determined by the program. Output from the program included Confidence Limits on the curve coefficients and the Linear Correlation Coefficient, $\mathrm{R}^{2}$, as statistical measures of the goodness-of-fit to the data. Confidence Limits are a measure of the uncertainty in the average value of a coefficient determined using sample data drawn from an existing population. The Linear Correlation Coefficient measures how well the data fit a linear mathematical model, with $\mathrm{R}^{2}=1$ providing a perfect fit. (Note that while a linear mathematical model is linear in the coefficients, it is not necessarily a linear function.) The program also provided Prediction Limits to measure the ability of the curve to estimate the value of a future observation obtained from the population. By statistical necessity, Prediction Limits must be wider than Confidence Limits to capture the additional uncertainty carried by the new data. These limits will be used in the next section to assess the applicability of the correlations to non-rectangular cavity geometries that are more characteristic of damage configurations. A discussion of these statistical concepts is provided in Morrison ${ }^{38}$.

The coefficient results developed using the SYSTAT TableCurve $2 D$ program are provided in Table 3 for the Mach 6 data, Table 4 for the Mach 10 data, and Table 5 for the combined Mach 6 and Mach 10 data sets. In all 
cases, the $\mathrm{R}^{2}$ is greater than 0.986 , implying a high degree of correlation with the linear model. Also provided at the 95\%, 99\%, and 99.9\% significance levels are the Upper Confidence Limits (UCL) and the Upper Prediction Limits (UPL). These limits provide successively wider coverage, depending on the allowable risk of the application.

Plots showing the baseline Mach $6 \mathrm{BF}_{\mathrm{AVG}}$ and $\mathrm{BF}_{\mathrm{MAX}}$ data comparison with the $99 \%$ Mach 6 correlations are given in Figure 14. Here, red open circles denote open cavities and red filled circles denote closed cavities. A close examination of the closed cavity (filled) $\mathrm{BF}_{\mathrm{AVG}}$ data reveals a slight rotation of the curve that is a result of pixelation error in the imaging. As the cavity size decreases, fewer pixels covering a larger area are present, resulting in lower heating averages with increased uncertainty. Corresponding plots for the baseline Mach 10 data compared with the 99\% Mach 10 correlations are given in Figure 15, where blue open squares represent open cavities and blue filled squares denote closed cavities. The Mach 10 Prediction Limit band for the $\mathrm{BF}_{\mathrm{AVG}}$ is significantly narrower than the Mach 6 band, indicative of the higher heating in the cavity providing lower uncertainty measurements. These data do not contain the apparent rotation noted for the Mach 6 results. Finally, Figure 16 presents plots showing the combined Mach 6 and Mach $10 \mathrm{BF}_{\mathrm{AVG}}$ and $\mathrm{BF}_{\mathrm{MAX}}$ data sets for comparison with the Mach 6 and Mach 10 correlation curves. The symbol nomenclature is consistent with the previous figures. The slight rotation between the Mach 6 and Mach 10 data sets is more visible when plotted together and now appears in the $\mathrm{BF}_{\mathrm{MAX}}$ as well. Each image is $640 \times 480$ pixels and covers the 18-inch plate length for the Mach 6 data to maximize viewing the downstream disturbance of the cavity. The camera was more narrowly focussed on the cavities for the Mach 10 tests over about 6 inches with the same $640 \times 480$ pixelation. This focussing improves the visualization by a factor of 3 for the Mach 10 results and the higher heating in the facility results in lower uncertainty. Accordingly, since the Mach 6 data exhibit wider explainable variation than the Mach 10 data, and since there is no apparent shift between the two tunnels, the Mach 10 correlations are believed to be more representative of the correct variation.

\section{Applicability of Correlation To Non-Rectangular Cavity Geometries}

Having established the correlations, it is necessary to assess their general validity using fully-laminar data not used in the original development. The non-rectangular-cavity geometries and non-baseline test condition data are compared with the correlations in this section as an independent check on the applicability of the relationships to heating predictions for damage environments. Non-baseline data acquired in the Mach 6 Tunnel will be compared with the Mach 6 baseline-data correlations, and non-baseline Mach 10 Tunnel data will be compared with the Mach 10 correlations for consistency. Non-baseline data for the Mach 6 experiments included variations in entry/exit angle, cross-sectional shape, planform shape, and slumping (non-uniform depth). Comparison of these $\mathrm{BF}_{\mathrm{AVG}}$ and $\mathrm{BF}_{\mathrm{MAX}}$ data are presented in Figure 17. All of these effects scatter within the $99 \%$ Prediction Limits, indicating that the correlation properly captures these cases for both open and closed cavity configurations. Variations in entry/exit angle and pressure gradient were examined in the Mach 10 experiments. These non-baseline data are compared with the 99\% Mach 10 correlations in Figure 18 and, again, the scatter is within the Prediction Limits for both open-flow and closed-flow cavities. The heating augmentation of non-baseline cavities simulating impact damage appears to be captured by the $99 \%$ Prediction Limits determined from the rectangular, baseline fully-laminar cavity correlations.

\section{Correlation Comparison with Computational Simulations}

Published computational simulations of wind tunnel test cases taken from T406 have been performed by R. Prabhu $^{39}$ for both open and closed cavity flow fields. Unpublished computational simulations of an open-flow cavity at several locations on the Orbiter windward surface at flight conditions to assess the influence of pressure gradient and real gas on cavity heating have been performed by M. V. Pulsonetti. All solutions were computed with the LAURA CFD code and they were fully converged and fully laminar for idealized rectangular geometries. The flooraveraged heating from these solutions is compared with the 99\% Mach 10 correlation in Figure 19, and all results are captured within the established Prediction Limits. The peak heating values $\left(\mathrm{BF}_{\mathrm{MAX}}\right)$ are not presented because they are grid-resolved at the top of the end wall where the geometry is a sharp 90-degree corner, resulting in extremely large values with high gradients due to the rapid flow turning. The measurements are unable to capture the heating variation at the computational resolution.

\section{Correlation Curve and Uncertainty Prediction}

Final expressions for the correlations are presented here. Substituting transformations of X and Y given by Eq. (6) into Eq. (7) yields a relationship for the variation of the Bump Factor that is given by 


$$
\left(\frac{H}{\delta}\right)^{\alpha}\left(1+\frac{L}{H}\right)^{\beta} B F=e^{a}\left[M_{e}^{\sigma} \operatorname{Re}_{\theta}^{\tau}\left(\frac{L}{\delta}\right)\right]^{b}
$$

where the values of the powers $\alpha, \beta, \sigma$, and $\tau$ are obtained from Table 2 , and the codfficients a and $\mathrm{b}$ are obtained from Table 3, Table 4, or Table 5, depending on the allowable uncertainty.

A relationship for the Bump Factor uncertainty, $\triangle \mathrm{BF} / \mathrm{BF}$, can be obtained by subtracting the linear relationship for the Correlation Curve from the linear relationship from the Upper Prediction Limit. This is given by

$$
\frac{\Delta B F}{B F}=e^{\left(a_{U P L}-a\right)}\left[M_{e}^{\sigma} \operatorname{Re}_{\theta}^{\tau}\left(\frac{L}{\delta}\right)\right]^{\left(b_{U P L}-b\right)}-1
$$

where $\triangle B F=B F_{U P L}-B F$ and, as above, the coefficients are obtained from the tables.

A specific example is provided here for the $99 \%$ Correlation derived from the Mach 10 data set. The floor averaged Bump Factor $\left(\mathrm{BF}_{\mathrm{AVG}}\right)$ is given by

$$
\left(\frac{H}{\delta}\right)^{3.3}\left(1+\frac{L}{H}\right)^{2.7} B F_{A V G}=0.04895\left[\operatorname{Re}_{\theta}^{0.1}\left(\frac{L}{\delta}\right)\right]^{2.8768}
$$

with

$$
\frac{\Delta B F_{A V G}}{B F_{A V G}}=1.7468\left[\operatorname{Re}_{\theta}^{0.1}\left(\frac{L}{\delta}\right)\right]^{-0.0021}-1 \approx 0.75
$$

providing a direct measure of the uncertainty in the $B F_{A V G}$ at given values of $R e_{\theta}$ and $(L / \delta)$. The endwall peak is provided by

$$
\left(\frac{H}{\delta}\right)^{3.3}\left(1+\frac{L}{H}\right)^{3.7} B F_{M A X}=1.30921\left[M_{e}^{0.2} \operatorname{Re}_{\theta}^{0.05}\left(\frac{L}{\delta}\right)\right]^{3.5079}
$$

with

$$
\frac{\Delta B F_{M A X}}{B F_{M A X}}=2.2669\left[M_{e}^{0.2} \operatorname{Re}_{\theta}^{0.05}\left(\frac{L}{\delta}\right)\right]^{-0.0027}-1 \approx 1.28
$$

To assess damage to the Orbiter, all local flow conditions can be obtained from numerical solutions through the flight trajectory, while damage location and planform geometry can be identified photographically during docking maneuvers with the International Space Station. For damage assessment, the only unknown is the physical depth, H, unless it is directly measured. However, since the thickness of the thermal protection system tiles is known over the entire vehicle, depth values from 0 to the maximum tile thickness can be assumed, allowing a heating assessment of cavity damage throughout the reentry trajectory. The Bump Factor correlation curves for the integrated heat load augmentation to the cavity floor and the cavity endwall that was derived from the Mach 10 data set are presented in Figure 20. Uncertainty Prediction Limits for $95 \%, 99 \%$, and $99.9 \%$ uncertainty are presented in Figure 21 . As demonstrated in Figure 21, the uncertainty in the correlation predictions will be larger or smaller than the provided example, as required by the allowable risk. 


\section{Cavity Centerline Distributions}

High-resolution, low-noise data acquired on two zero-pressure gradient models tested in the Mach 10 (T406) allow a clear examination of the centerline heating of an open $(\mathrm{L} / \mathrm{H}=7.2$, Figure $22 \mathrm{a})$ and a closed cavity $(\mathrm{L} / \mathrm{H}=20$, Figure 22b). The BF profiles for the short cavity are tightly collapsed, as indicated by the open-symbol data, but the profiles within the cavity separate from the group when transitional flow is indicated downstream. This implies that the intial boundary layer instability is occuring in the separation shear layer over the cavity. The same may be stated for the longer cavity where the disturbance is even more highly amplified by the vortical interactions occuring on the sidewall and floor. (Note the scale change between these figures.) The long cavity experiences signficant heating increases for Runs 42 and 43 where the cavity endwall temperature has increased beyond the allowable range of the phosphor, thus saturating the measurement system and causing data dropout.

A wide range of open and closed cavity centerline data taken from T6888 are presented in Figure 23. As with the previous discussion, the fully-laminar data have similar distributions and levels until transitional/turbulent flow is present. The similarity of the heating profiles provided here, the collapse of the open and closed heating data to single-curve correlations, and the decay rate correlations to be presented in the next section call to question the validity of the classical definitions of open, transitional, and closed flow cavities as applied to hypersonic laminar boundary layer environments.

\section{Cavity-Exit Heating Decay Rate}

Laminar-exit heating data taken from T406 (see Figure 22) have been extracted and normalized by according to

$$
\frac{(B F-1)}{\left(B F_{M A X}-1\right)} \quad \text { and } \quad \frac{\left(X-X_{M A X}\right)}{H}
$$

where the subscript $M A X$ refers to the value and location of the centerline peak heating. Results of this normalization are presented in Figure 24 for a short $(\mathrm{L} / \mathrm{H}=7.2)$ cavity and Figure 25 for a long $(\mathrm{L} / \mathrm{H}=20)$ cavity. The TableCurve $2 D$ program was used to develop a curve fits for each data set and both are plotted as dashed lines on each figure for comparison. Differences between these two curves occur mainly in the knee region around $\left(X-X_{M A X}\right) / H=2$. As an engineering model, the laminar-exit heating decay to the undisturbed state (solid line) is sufficiently captured by

$$
\frac{(B F-1)}{\left(B F_{M A X}-1\right)}=\exp \left[\frac{-\left(X-X_{M A X}\right)}{H}\right]
$$

\section{Engineering Model for Cavity Heating}

A conservative engineering (99\% uncertainty) model for estimating the heating augmentation of a fully laminar cavity can now be specified. Since the floor heating is approximately constant over the center, the $\mathrm{BF}_{\mathrm{AVG}}$ variation from Eq. (10) can be applied over the region from $\mathrm{X} / \mathrm{L} \approx 0.05$ to $\mathrm{X} / \mathrm{L} \approx 0.85$. The $\mathrm{BF}$ value of 1 can be applied along the upstream and sides of the cavity and linearly interpolated to the floor in these regions. Inside the cavity on the downstream end, $\mathrm{BF}$ can be varied linearly from $\mathrm{X} / \mathrm{L} \approx 0.85$ to the $\mathrm{BF}_{\mathrm{MAX}}$ (Eq. 12) on the endwall at $\mathrm{X} / \mathrm{L}=1.0$. The cavity heating wake can be exponentially decayed according to Eq. (15). Uncertainties $(\triangle \mathrm{BF} / \mathrm{BF})$ at the desired risk can be applied to both $\mathrm{BF}_{\mathrm{AVG}}$ and $\mathrm{BF}_{\mathrm{MAX}}$ according to Eq. (11) and Eq. (13), respectively.

\section{Concluding Remarks}

A massive cavity heating database was generated via the Space Shuttle Return-To-Flight Program to support tool development for impact damage assessment of the Orbiter thermal protection system. These data were previously documented and they formed the basis of the current laminar, bounding-analysis methods that are incorporated into the Cavity Heating Tool (Version 3). Accordingly, because this type of analysis captures the global extent of the anticipated heating variation, the tools are known to be overly conservative, potentially producing unnecessary extra-vehicular excursions for damage repair.

This paper provides new laminar-cavity heating correlations of the damage-assessment database. Using known geometry information and surface flow conditions, specific correlations are provided for the floor-averaged bump factor (or heating augmentation), the maximum endwall bump factor, and a simple analytical relationship for the downstream heating decay rate. The analysis provides quantifiable uncertainties of the heating predictions. 
Specifically provided are Confidence Limits on curve coefficients to statistically address the quality of the fit, and Prediction Limits to address the region of applicability — all at 95\%, 99\%, and $99.9 \%$ uncertainty levels.

The correlations were developed using just the rectangular-cavity geometries. The region of applicablity was assessed using non-rectangular geometries with variations in planform, profile, and cross-section. Computational simulations of the wind tunnel data and flight provided very favorable comparisons with the correlations, developing significant confidence in their utility.

Very importantly, these correlations collapse the open-flow and closed-flow cavity-heating database into a single-curve parameterization, thereby removing discontinuities and restrictions inherent in the implemented method. Because of this collapse, the uncertainty estimates are well defined, potentially removing current overconservatism.

Finally, the combination of these correlations provides the necessary building-block elements for defining a damage-assessment heating model of impact-induced cavities on the Shuttle Orbiter. Other future vehicle programs should benefit from their use.

\section{References}

1 Fletcher, L.S., Briggs, D.G., and Page, R.H., “A Review of Heat Transfer in Separated and Reattached Flows," AIAA 70-767, July 1970.

2 Nestler, D.E., "The Effects of Surface Discontinuities on Convective Heat Transfer in Hypersonic Flow," AIAA Paper 850971, AIAA 20th Thermophysics Conference, Williamsburg, VA, June 1985.

3 Wood, William A., Pulsonetti, Maria V., Everhart, Joel L., and Bey, Kim S., "Assessment of Laura for Laminar Supersonic Shallow Cavities," Presented at 34th AIAA Fluid Dynamics Conference, Portland OR, June 28-July 1, 2004.

4 Pulsonetti, M.V. and Wood, W.A., "Computational Aerothermodynamic of Space Shuttle Orbiter Tile Damage - Open Cavities", AIAA 2005-4679, 38th AIAA Thermo-physics Conference, Toronto, Canada, June 6-9, 2005.

5 Galenter, S.A., "An Experimental Summary of Plasma Arc Exposures of Space Shuttle High-Temperature Reusable Surface Insulation Tile Array with a Single Missing Tile (Conducted at the Ames Research Center)," NASA SP-379, Paper 18, 1975.

6 Nestler, D.E., "Laminar Heat Transfer to Cavities in Hypersonic Low Density Flow," Proceedings 3rd International Heat Transfer Conference, Chicago, IL, Vol. 2, 1966.

7 Nestler, D.E., "Hypersonic Laminar Cavity Heat Transfer," Presented at 4th International Heat Transfer Conference, August 31-September 5, 1970, Versailles, France.

8 Nicoll, K.M., “An Experimental Investigation of Laminar Hypersonic Cavity Flows Part II, Heat Transfer and Recovery Factors Measurements," ARL 63-73.

9 Nicoll, K.M., “A Study of Laminar Hypersonic Cavity Flows,” AIAA Journal, Vol. 2, No. 9, September 1964.

${ }^{10}$ Wyborny, W., Kabelitz, H.P. and Schepers, H.J., "Hypersonic Investigation on the Local and Average Heat Transfer in Cavities and after Steps of Bodies of Revolution," AGARD Conference Proceedings No. 19, Fluid Physics of Hypersonic Wakes, 1967.

${ }^{11}$ Cheatwood, F. McNeil, Merski, N. Ronald, Jr., Riely, Christopher J., and Mitcheltree, Robert A., "Aerothermodynamic Environment Definition for the Genesis Sample Return Capsule," AIAA 2001-2889, Presented at 35th AIAA Thermophysics Conference, Anaheim, CA, June 11-14, 2001.

${ }^{12}$ Hahn, Mansop, "Experimental Investigation of Separated Flows over a Cavity at Hypersonic Speed," AIAA No. 68-672, AIAA Journal, Vol. 7, No. 6, June 1969, pp. 1092-1098.

${ }^{13}$ Nestler, D.E., "An Experimental Study of Cavity Flow on Sharp and Blunt Cones at Mach 8," AIAA 81-0335, AIAA 19th Aerospace Sciences Meeting, St. Louis, Missouri, January 12-15, 1981.

${ }^{14}$ Everhart, Joel L., Alter, Stephen J., Merski, N. Ronald, Wood, William A., and Prabhu, Ramadas K., "Pressure Gradient Effects on Hypersonic Cavity Flow Heating," AIAA 2006-0185, Presented at 44th AIAA Aerospace Sciences Meeting and Exhibit, Reno, NV, January 9-12, 2006.

${ }^{15}$ Everhart, Joel L., Berger, Karen T., Bey, Kim S., Merski, N. Ronald, and Wood, William A., "Cavity Heating Experiments Supporting Shuttle Columbia Accident Investigation,” NASA TM 2006-214528, 2006.

${ }^{16}$ Everhart, Joel L., Berger, Karen T., Brauckmann, Gregory J, Merski, N. Ronald, and Wood, William A., "Parametric Cavity Heating Experiments Supporting Shuttle Orbiter Return To Flight,” NASA JSC EG-SS-06-04, 2007.

${ }^{17}$ Everhart, Joel L., Berger, Karen T., Merski, N. Ronald, Wood, William A., Hollingsworth, Kevin E., Hyatt, Andrew J., and Prabhu, Ramadas K., "Aero-Heating of Shallow Cavities in Hypersonic Freestream Flow," NASA JSC EG-SS-06-07, 2007.

${ }^{18}$ Anderson, Brian, Hyatt, Jay, Wang, K.C., Everhart, Joel, Greene, Frank, Pulsonetti, Maria, Wood, Bill, Bourland, Gary, and Cassady, Amy, “The Cavity Heating Tool," Boeing Technical Memorandum ATA-AH-TM-2005-079, The Boeing Company, NASA Space Systems, Houston, TX, Dec. 7, 2005.

${ }^{19}$ Charwat, A.F., Roos, J.N., Dewey, C.F., Jr., and Hitz, J.A., “An Investigation of Separated Flows - Part I, The Pressure Field,” Journal of Aerospace Sciences, Vol. 28, No. 6, June 1961, pp. 457-470.

${ }^{20}$ Charwat, A.F., Dewey, C.F., Roos, J.N., and Hitz, J.A., "An Investigation of Separated Flows - Part II, Flow in the Cavity and Heat Transfer,” Journal of Aerospace Sciences, Vol. 28, No. 7, pp. 513-527, July 1961. 
${ }^{21}$ Berry, Scott. A., Horvath, Thomas J., Greene, Francis A., Kinder, Gerald R., and Wang, K. C., "Overview of Boundary Layer Transition Research in Support of Orbiter Return To Flight." AIAA Paper 2006-2918, June 2006.

${ }^{22}$ Stallings, Robert L., Jr., Wilcox, Floyd J., Jr., and Forrest, Dana K., "Measurements of Forces, Moments, and Pressures on a Generic Store Separating From a Box Cavity at Supersonic Speeds," NASA TP 3110, Sept. 1991.

${ }^{23}$ Micol, J.R., "Langley Aerothermodynamic Facilities Complex, Enhancements and Testing Capabilities," AIAA Paper 980147, January 1998.

${ }^{24}$ Merski, N.R., "Global Aeroheating Wind Tunnel Measurements Using Improved Two-Color Phosphor Thermography Method," Journal of Spacecraft and Rockets, Vol. 36, No. 2, 1999, pp. 160-170.

${ }^{25}$ Everhart, Joel L., Hollingsworth, Kevin E., Erickson, David W., Merski, N. Ronald, and Prabhu, Ramadas K., "Real Cavity Heating Experiments Supporting Shuttle Orbiter Return To Flight," NASA JSC EG-SS-07-01, 2007.

${ }^{26}$ Hollis, B.R., "Real-Gas Flow Properties for NASA Langley Research Center Aerothermodynamic Facilities Complex Wind Tunnels," NASA CR 4755, September 1996.

${ }^{27}$ Buck, G.M., and Vasques, P., "An Investment Ceramic Slip-Casting Technique for Net-Form, Precision, Detailed Casting of Ceramic Models," U.S. Patent 5,266,252, November 1993.

${ }^{28}$ Buck, G.M., Powers, M.A., Nevins, S.C., Griffith, M.S., Verneris, P.H., and Wainwright, G.A., "Rapid Fabrication of Flat Plate Cavity Phosphor Thermography Test Models for Shuttle Return-to-Flight Aero-Heating," NASA TM 2006-214508.

${ }^{29}$ Merski, N.R., "An Improved Two-Color Relative-Intensity Phosphor Thermography Method for Hypersonic Wind Tunnel Aeroheating Measurements," NASA CDTP-1017, February 2001.

${ }^{30}$ Campbell, Charles H., Wang, K. C., An, Michael Y., Tam, Luen T., Bouslog, Stanley A., "Orbiter Boundary-Layer Working Group, Numerical Flow Field Analysis Data," JSC-26816, December, 1994.

${ }^{31}$ Gnoffo, P.A., Gupta, R.N., and Shinn, J.L., "Conservation Equations and Physical Models for Hypersonic Air Flows in Thermal and Chemical Nonequilibrium," NASA TP 2867, February 1989.

32 Gnoffo, P.A., An Upwind-Biased, Point-Implicit Relaxation Algorithm for Viscous, Compressible Perfect Gas Flows,” NASA TP 2953, February 1990.

${ }^{33}$ Fay, J.A. and Riddell, F.R., "Theory of Stagnation Point Heat Transfer in Dissociated Air," Journal of Aeronautical Sciences, Vol. 25, No. 2, 1958, pp. 73-85.

${ }^{34}$ Horvath, Thomas J., Berry, Scott. A., Merski, N. Ronald, Berger, Karen T., Buck, Gregory M., Liechty, Derek S., and Schneider, Steven P., "Shuttle Damage/Repair from the Perspective of Hypersonic Boundary Layer Transition Experimental Results." AIAA Paper 2006-2919, June 2006.

35 Dewey, C. F., Jr., "Measurements in Highly Dissipatitive Region of Hypersonic Flows. Part II. The Near Wake of a Blunt Body at Hypersonic Speeds," Ph.D. thesis, 1963, California Institute of Technology.

${ }^{36}$ Lamb, J.P., "Convective Heat Transfer Correlations for Planar, Supersonic, Separated Flows”, Trans. ASME, Series C, Vol. 102, No. 2, May 1980, pp. 351-356.

${ }^{37}$ Lamb, J.P., "Analysis and Correlation of Convective Heat Transfer Measurements for Open Cavities in Supersonic Flow," AIAA 80-1526, July 1980.

${ }^{38}$ Morrison, Donald F., “Applied Linear Statistical Methods," Prentice-Hall, Inc., Englewood Cliffs, New Jersey, 1983.

${ }^{39}$ Prabhu, Ramadas K., “Comparison of LAURA CFD Predictions with Experimental Heating," NASA CR (submitted for publication), 2007. 


\section{Tables}

Table 1.- Cavity heating database test parameter ranges at cavity entrance.

\begin{tabular}{|cc|}
\hline Parameter & Range \\
\hline $\mathbf{M}_{\mathbf{e}}$ & 1.75 to 3.20 \\
$\mathbf{R e}_{\theta}$ & 150 to 725 \\
$\mathbf{R e}_{\theta} / \mathbf{M}_{\mathbf{e}}$ & 60 to 340 \\
$\mathbf{L} / \mathbf{H}$ & 7 to 30 \\
$\mathbf{H} / \boldsymbol{\delta}$ & 0.1 to 2.4 \\
$\mathbf{L} / \delta$ & 0.5 to 40 \\
\hline
\end{tabular}

Table 2.- Final cavity correlation coefficient powers.

\begin{tabular}{|c|c|c|}
\cline { 2 - 3 } Power & $\mathbf{B F}_{\mathbf{A V G}}$ & $\mathbf{B F}_{\mathbf{M A X}}$ \\
\hline $\boldsymbol{\alpha}$ & 3.30 & 3.30 \\
\hline $\boldsymbol{\beta}$ & 2.70 & 2.70 \\
\hline $\boldsymbol{\sigma}$ & 0.00 & 0.20 \\
\hline $\boldsymbol{\tau}$ & 0.10 & 0.05 \\
\hline
\end{tabular}

Table 3.- Cavity correlation coefficient values for $y=a+b x$ fit of Mach 6 baseline data.

\begin{tabular}{|c|ccc|ccc|}
\cline { 2 - 7 } \multicolumn{1}{c|}{} & \multicolumn{3}{c|}{ BF $_{\text {AvG }}$} & \multicolumn{3}{c|}{ BF $_{\text {MAX }}$} \\
\cline { 2 - 7 } \multicolumn{1}{c|}{ Correlation } & -2.8251 & 2.9650 & 0.9882 & -0.6305 & 3.8695 & 0.9895 \\
$\mathbf{9 5 \%}$ UCL & -2.3775 & 2.9754 & & -0.0697 & 3.8792 & \\
$\mathbf{9 5 \%}$ UPL & -2.7563 & 2.9441 & & -0.5409 & 3.8407 & \\
$\mathbf{9 9 \%}$ UCL & -2.1834 & 2.9715 & & 0.1707 & 3.8737 & \\
$\mathbf{9 9 \%}$ UPL & -2.7237 & 2.9540 & & -0.5137 & 3.8588 & \\
$\mathbf{9 9 . 9 \%}$ UCL & -1.9601 & 2.9730 & & 0.4430 & 3.8769 & \\
$\mathbf{9 9 . 9 \%}$ UPL & -2.8251 & 2.9650 & & -0.6305 & 3.8695 & \\
\hline
\end{tabular}

Table 4.- Cavity correlation coefficient values for $y=a+b x$ fit of Mach 10 baseline data.

\begin{tabular}{|c|c|c|c|c|c|c|}
\hline & \multicolumn{3}{|c|}{$\mathrm{BF}_{\mathrm{AVG}}$} & \multicolumn{3}{|c|}{$\mathrm{BF}_{\text {MAX }}$} \\
\hline & a & b & DF Adj $R^{2}$ & a & b & DF Adj $R^{2}$ \\
\hline Correlation & -3.0169 & 2.8768 & 0.9911 & 0.2694 & 3.5079 & 0.9867 \\
\hline 95\% UCL & -2.9551 & 2.8862 & & 0.3547 & 3.5247 & \\
\hline 95\% UPL & -2.6089 & 2.8792 & & 0.8704 & 3.5122 & \\
\hline 99\% UCL & -2.9033 & 2.8654 & & 0.4315 & 3.4942 & \\
\hline 99\% UPL & -2.4692 & 2.8745 & & 1.0772 & 3.5051 & \\
\hline 99.9\% UCL & -2.9092 & 2.8918 & & 0.4154 & 3.5367 & \\
\hline 99.9\% UPL & -2.3178 & 2.8806 & & 1.2985 & 3.5153 & \\
\hline
\end{tabular}

Table 5.- Cavity correlation coefficient values for $y=a+b x$ fit of combined Mach $6 /$ Mach 10 baseline data.

\begin{tabular}{|c|ccc|ccc|}
\cline { 2 - 7 } \multicolumn{1}{c|}{} & \multicolumn{3}{c|}{$\mathbf{B F}_{\text {AvG }}$} & \multicolumn{3}{c|}{ BF $_{\text {MAX }}$} \\
\hline Correlation & -3.1703 & 3.0060 & 0.9886 & -0.2038 & 3.6977 & 0.9877 \\
$\mathbf{9 5 \%}$ UCL & -3.9370 & 3.0048 & & -0.1129 & 3.6989 & \\
$\mathbf{9 5 \%}$ UPL & -2.5960 & 3.0058 & & 0.5263 & 3.6979 & \\
$\mathbf{9 9 \%}$ UCL & -3.0693 & 3.0044 & & -0.0838 & 3.6993 & \\
$\mathbf{9 9 \%}$ UPL & -2.4126 & 3.0058 & & 0.7593 & 3.6979 & \\
$\mathbf{9 9 . 9 \%}$ UCL & -3.0388 & 3.0030 & & -0.0475 & 3.6984 & \\
$\mathbf{9 9 . 9 \%}$ UPL & -2.1966 & 3.0055 & & 1.0339 & 3.6978 & \\
\hline
\end{tabular}


Figures

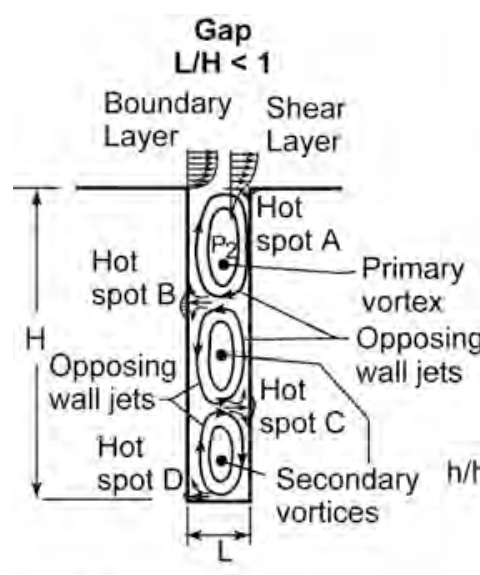

- Extensive data

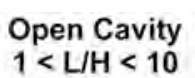

$1<$ L/H $<10$

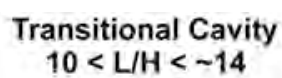

Transitional Cavity
$10<\mathrm{L} / \mathrm{H}<\sim 14$

\section{Closed Cavity L $/ \mathrm{H}>\sim 14$}

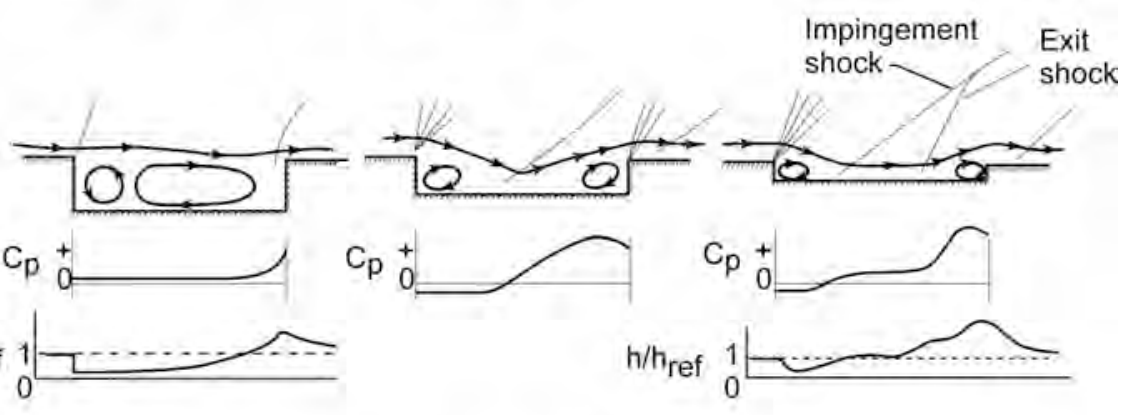

- Unstable flow solution

- Stable flow solution - Limited data
- Stable flow solution

- Representative laminar and turbulent flow data

Figure 1. Cavity flow regimes.

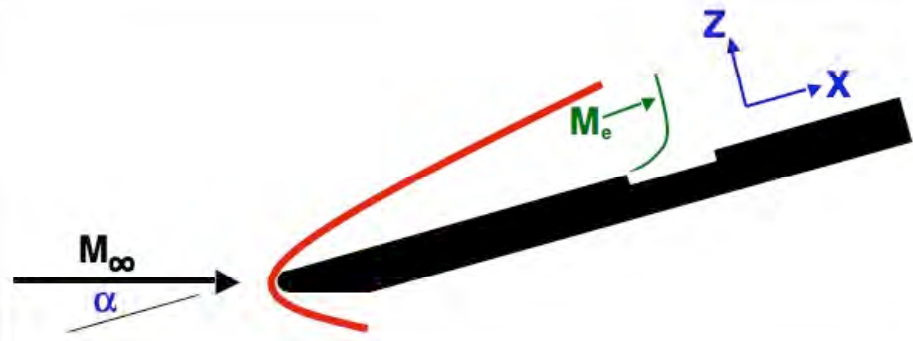

Figure 2. Model coordinate system.

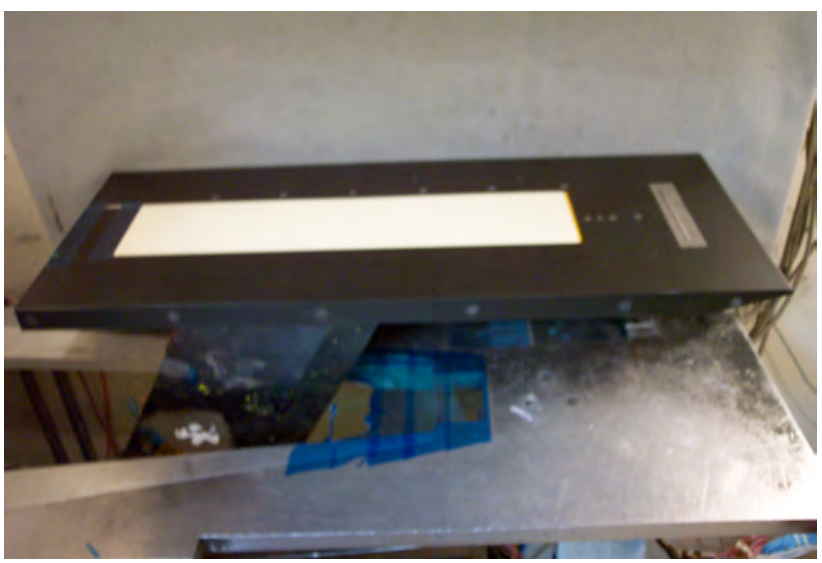

Figure 3. Baseline model with 4-inch by 18-inch ceramic inserts used in Mach 6 for T6888.

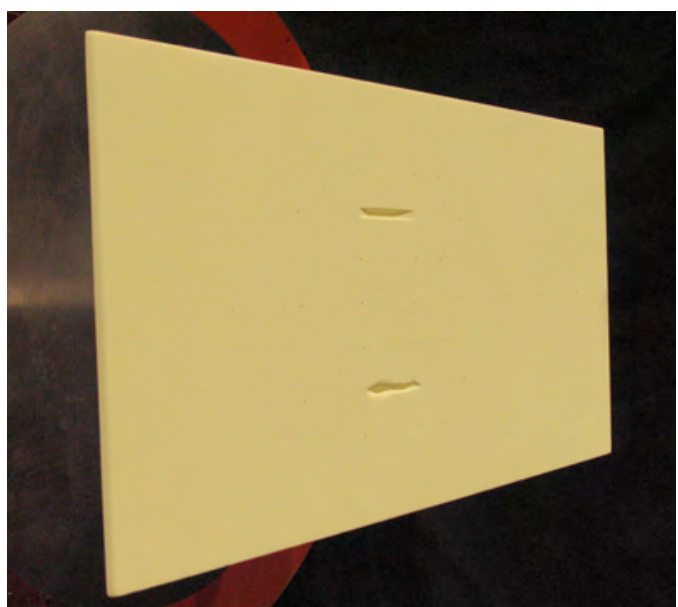

Figure 4. Full-surface ceramic model used in Mach 10 Test 423. Idealized cavity on top and real cavity geometry on bottom. 

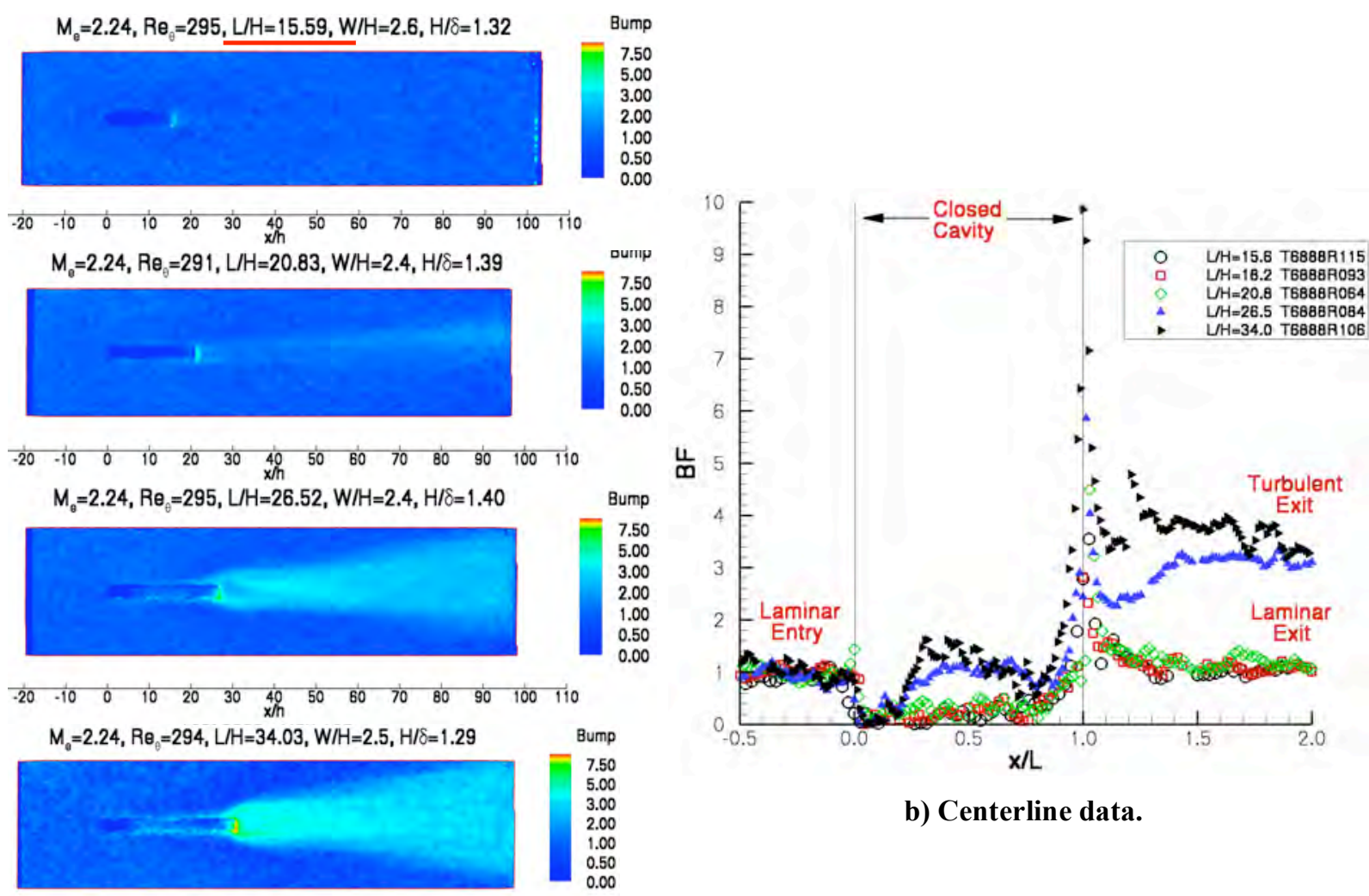

b) Centerline data.

$\begin{array}{cccccccccccccc}-20 & -10 & 0 & 10 & 20 & 30 & 40 & 50 & 60 & 70 & 80 & 90 & 100 & 110\end{array}$

a) Image data.

Figure 5. Closed-cavity length effect on laminar-entry heating. Test $6888, M_{e}=2.25, \operatorname{Re}_{\theta}=300, H / \delta=1.35$.

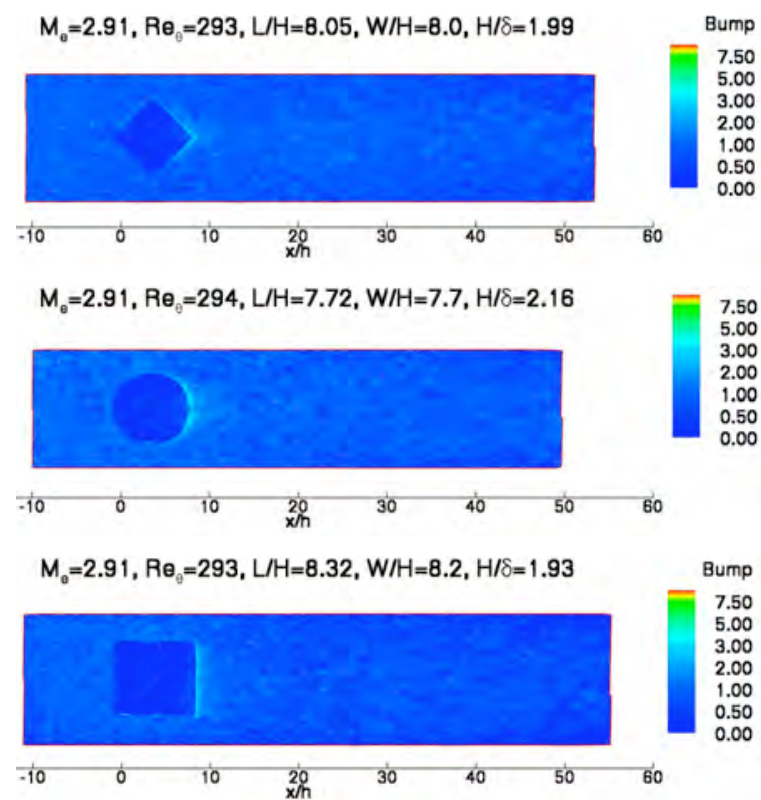

a) Image data.

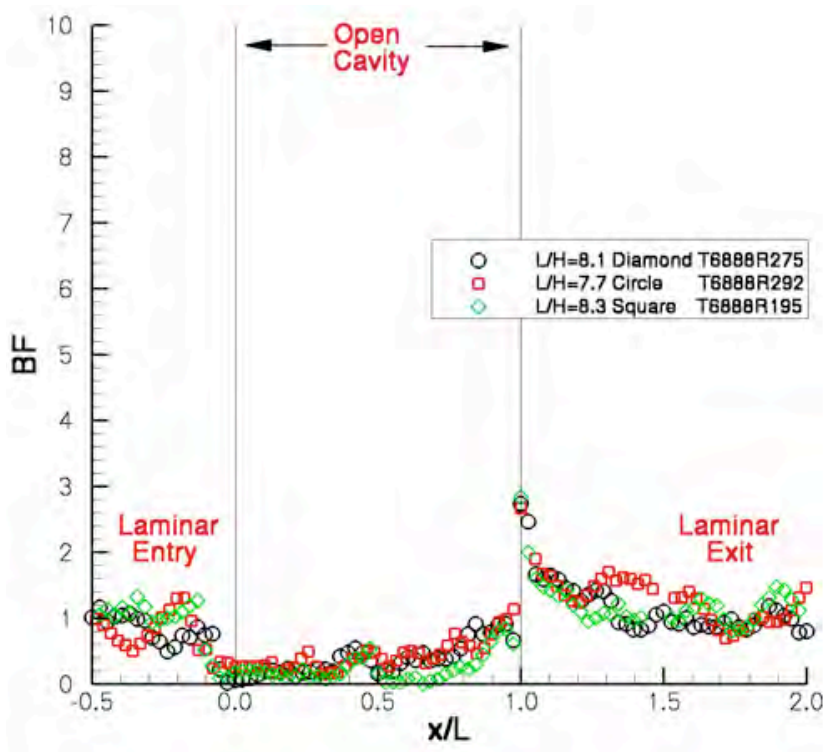

b) Centerline data.

Figure 6. Planform effect on open-cavity laminar-entry heating. Test $6888, M_{e}=2.91, \operatorname{Re}_{\theta}=300, H / \delta=2$. 

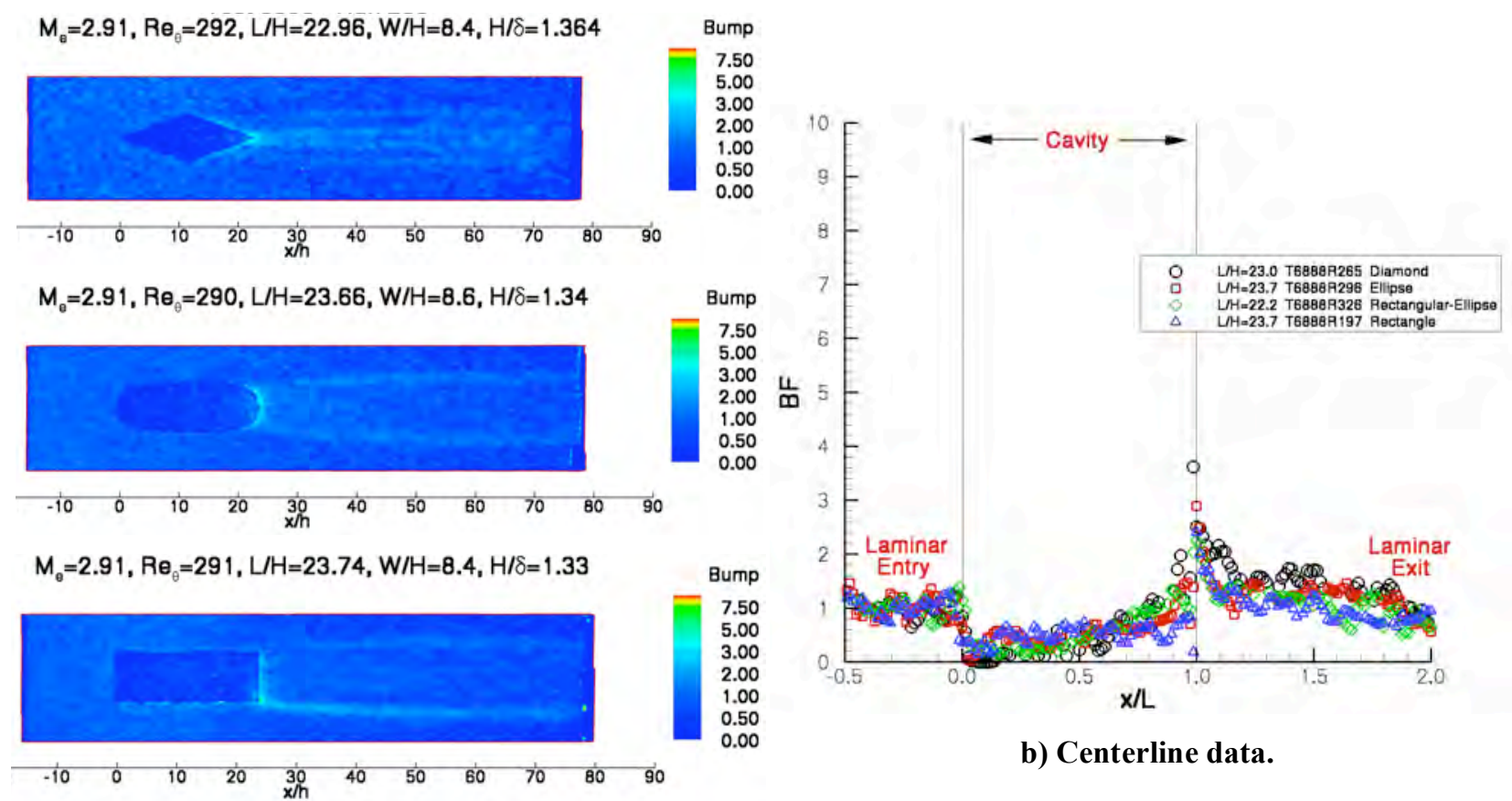

b) Centerline data.

a) Image data.

Figure 7. Planform effect on closed-cavity laminar-entry heating. Test $6888, M_{e}=2.91, R_{\theta}=300, H / \delta=1.35$
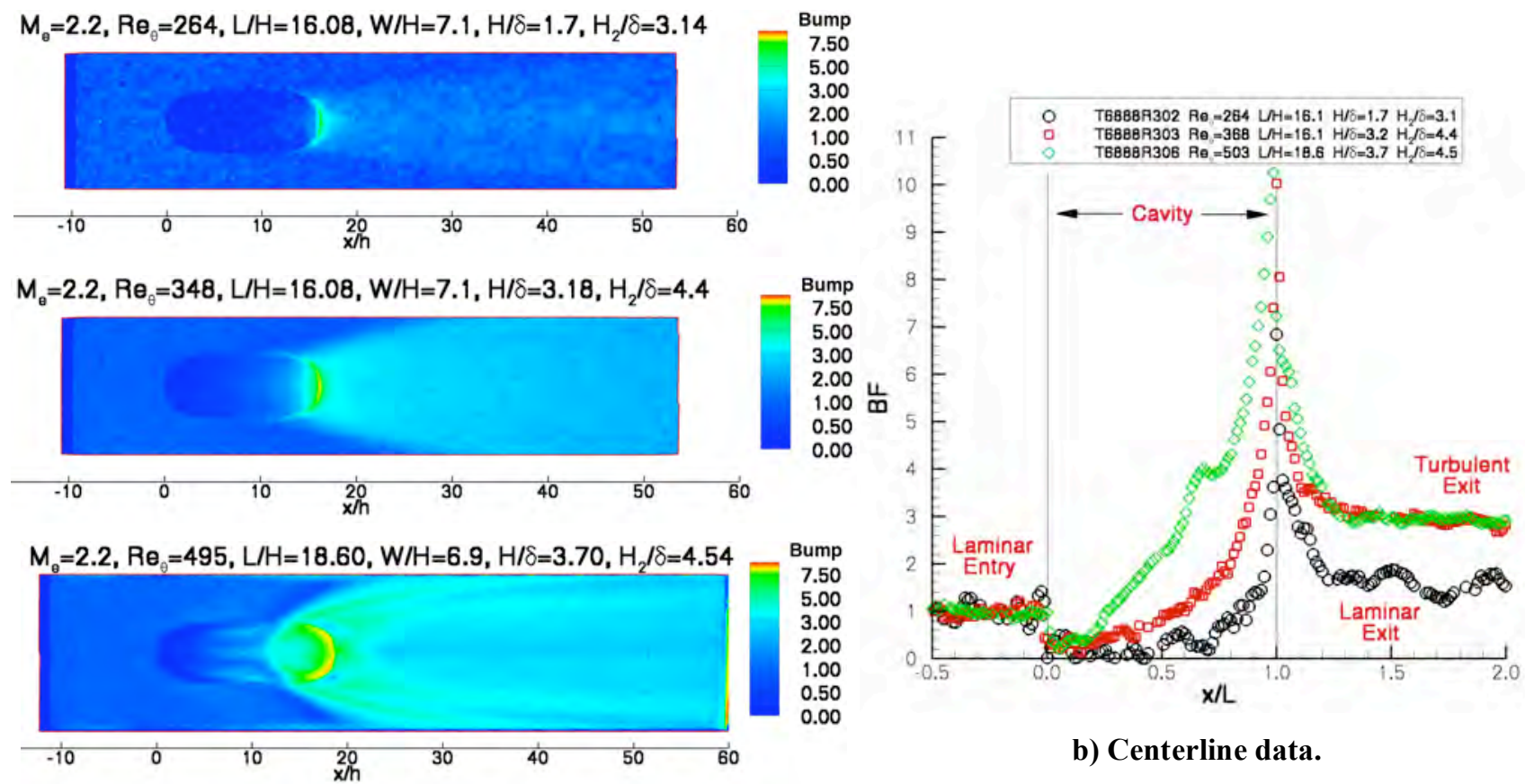

b) Centerline data.

a) Image data.

Figure 8. Downstream profile slumping effect on closed-cavity laminar-entry heating. Test $6888 \mathrm{M}_{\mathrm{e}}=\mathbf{2 . 9 1}$. 

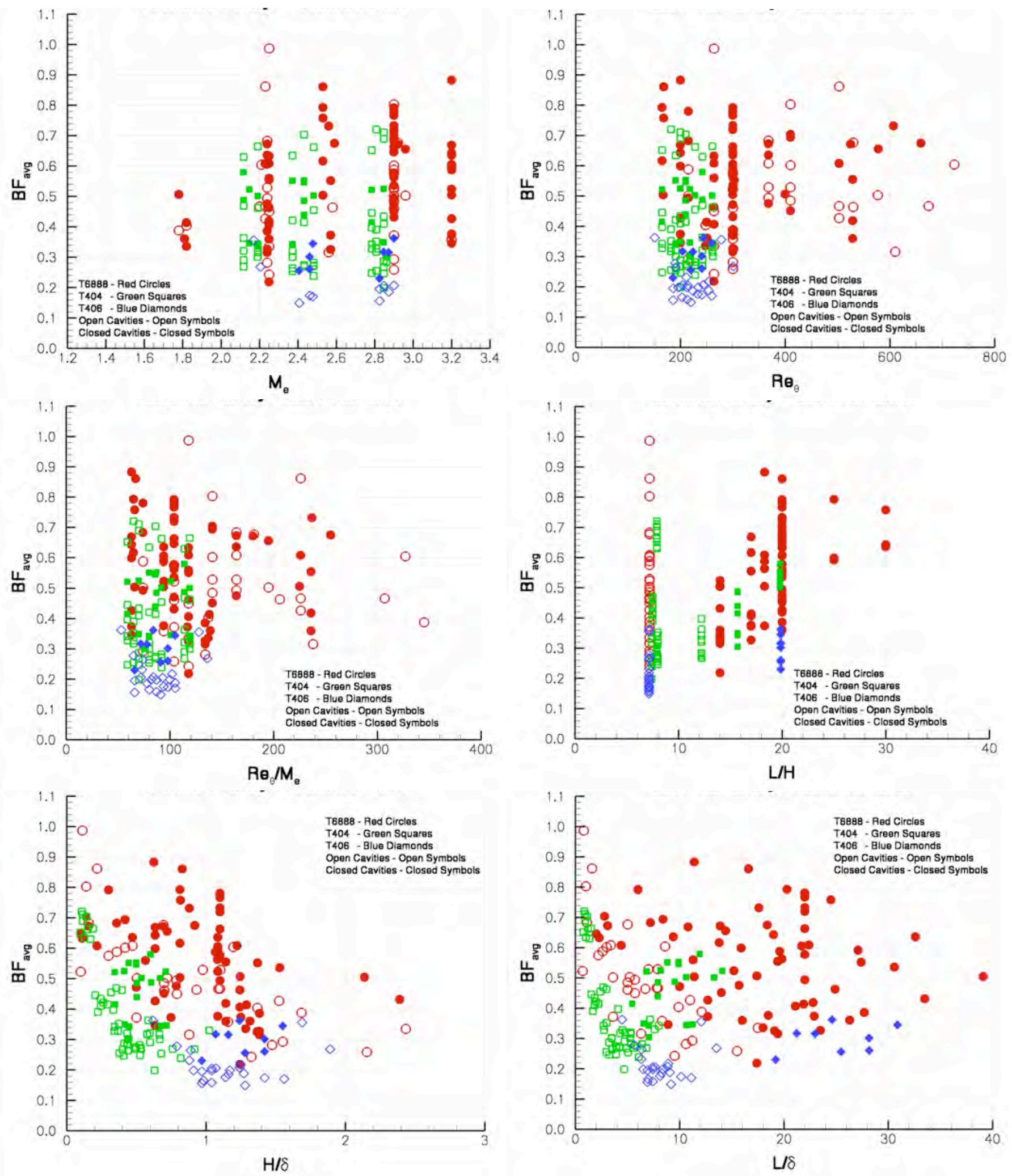

Figure 9. Variation of cavity floor average heating augmentation with test parameters. 


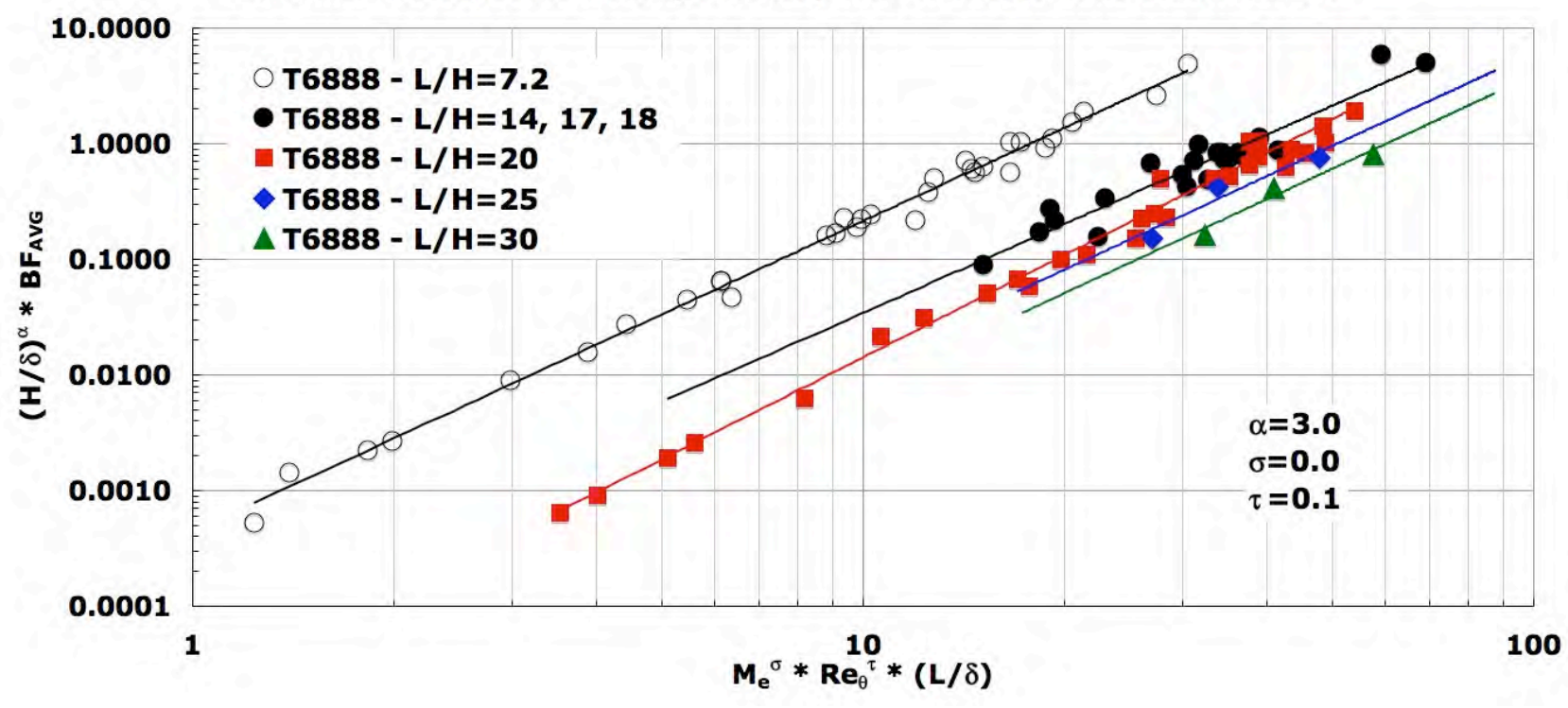

Figure 10.- Initial transformation of T6888 floor-averaged bump factor.

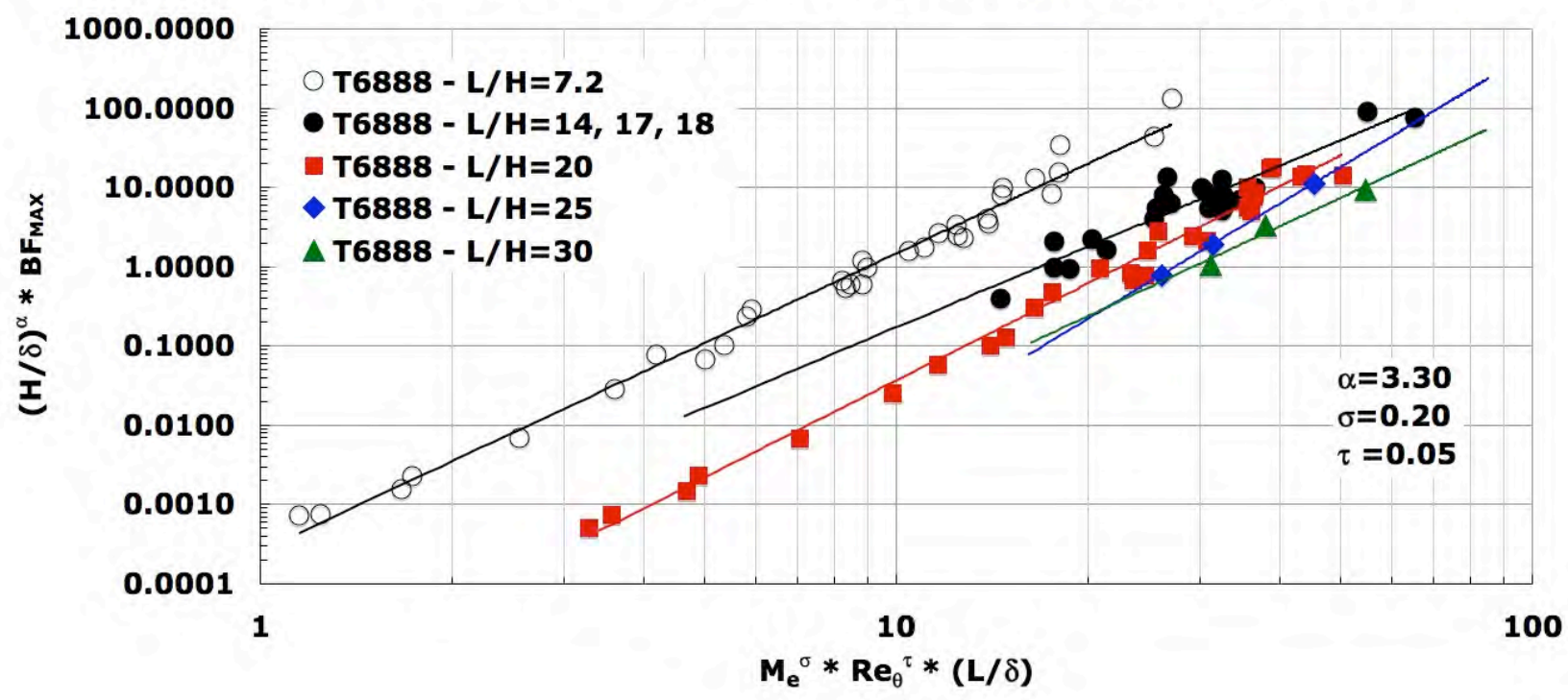

Figure 11.- Initial transformation of T6888 maximum endwall bump factor. 


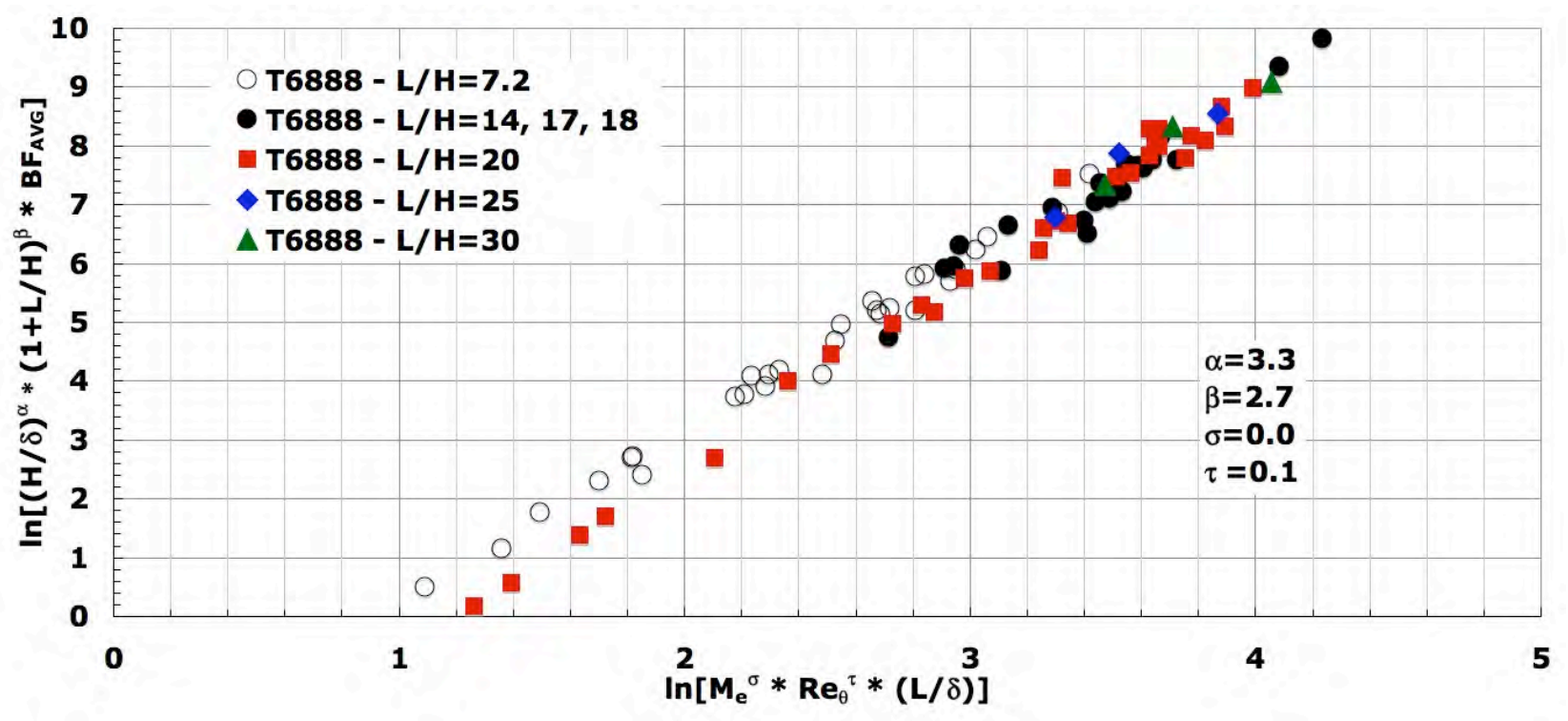

Figure 12. Transformation of T6888 floor-averaged bump factor.

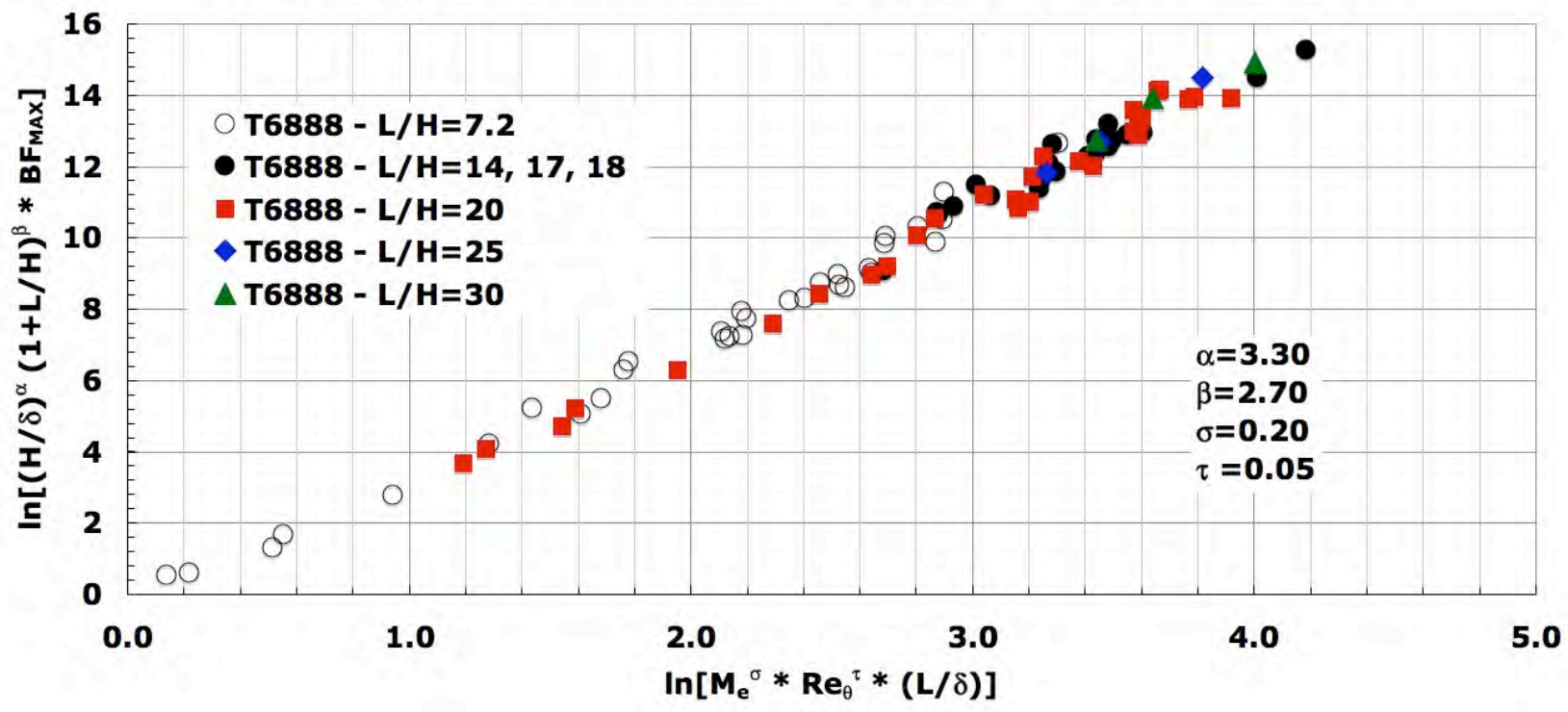

Figure 13. Transformation of T6888 maximum endwall bump factor. 


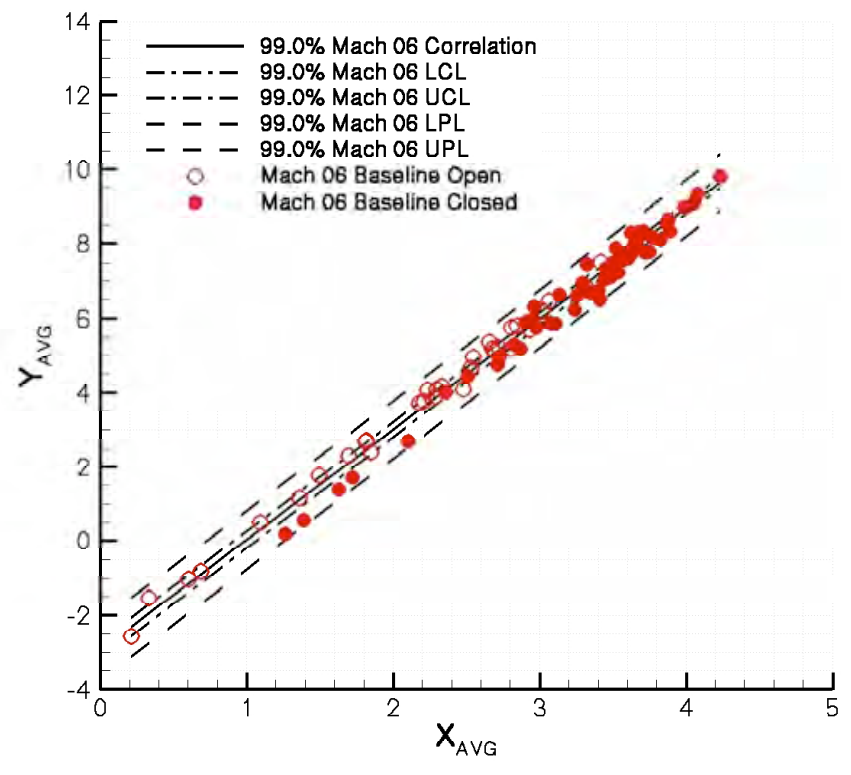

a) Cavity floor correlation.

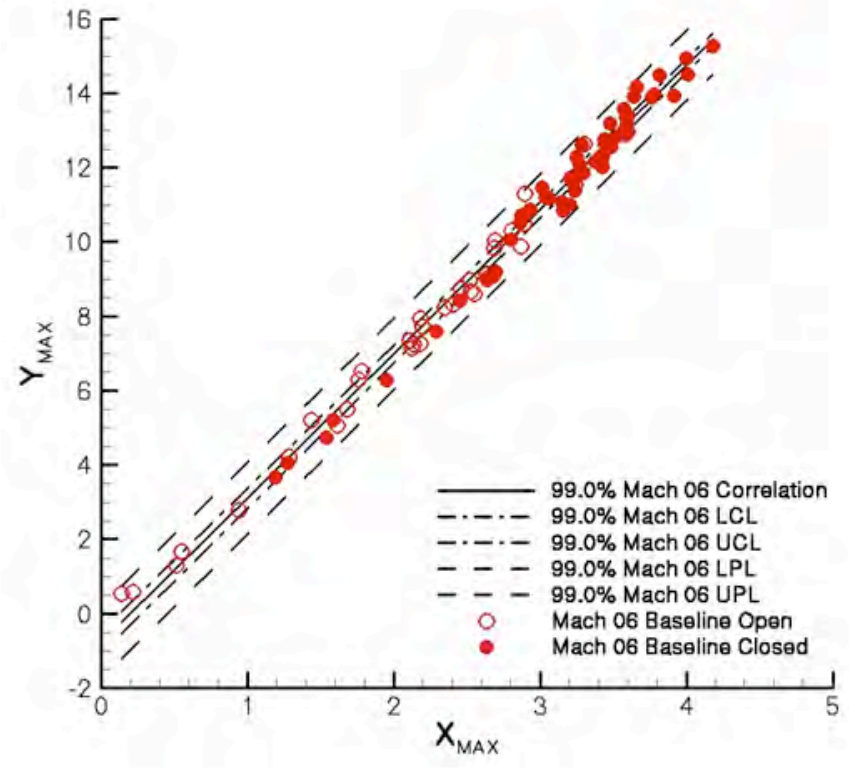

b) Cavity endwall maximum correlation.

Figure 14. Comparison of baseline Mach 6 correlation parameters with 99\% Mach 6 correlation.

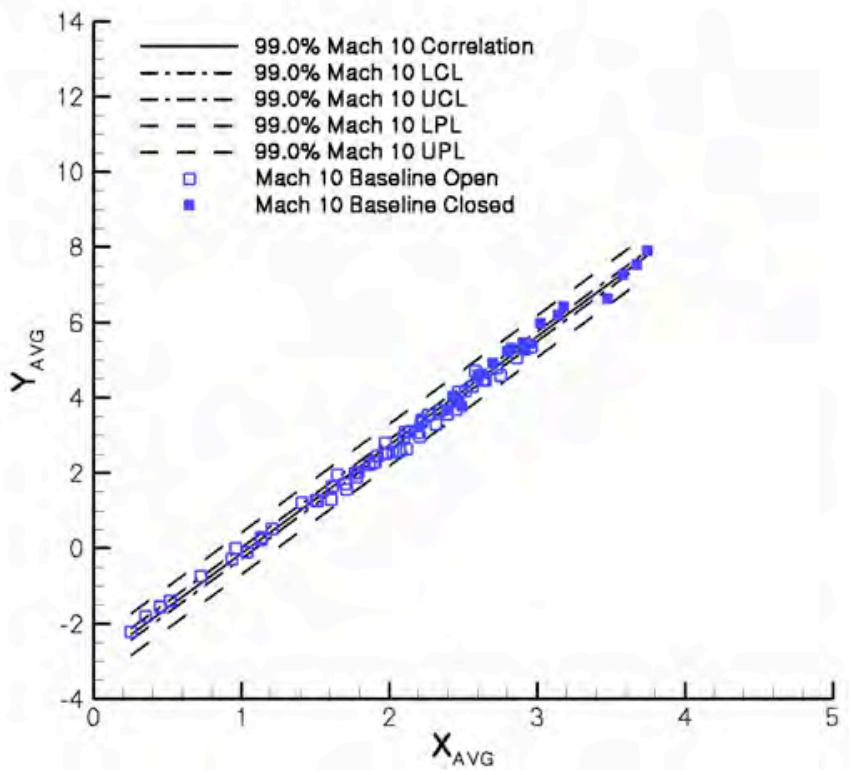

a) Cavity floor correlation.

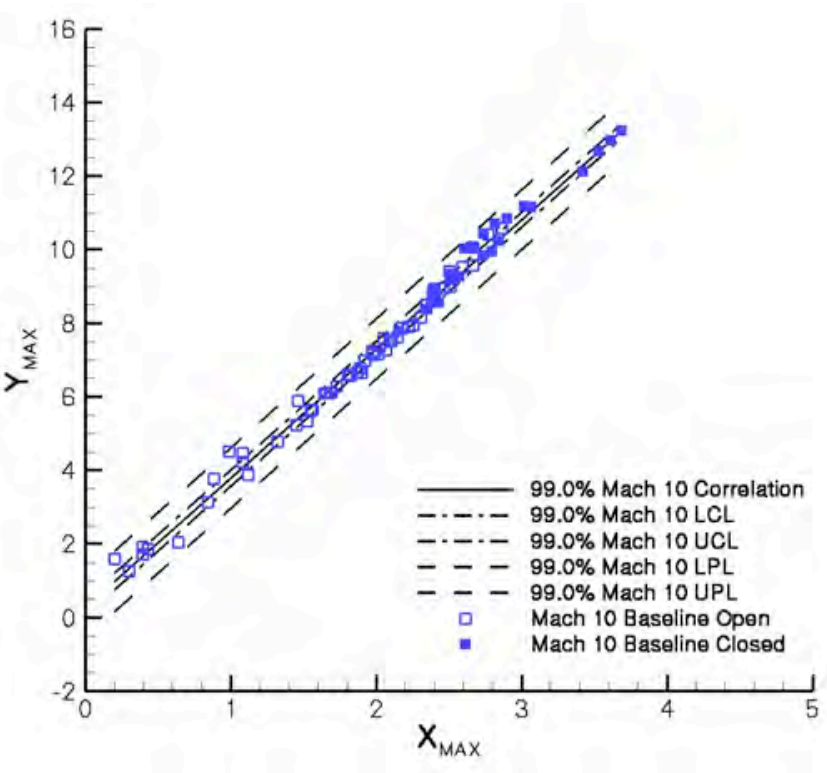

b) Cavity endwall maximum correlation.

Figure 15. Comparison of baseline Mach 10 correlation parameters with $99 \%$ Mach 10 correlation. 


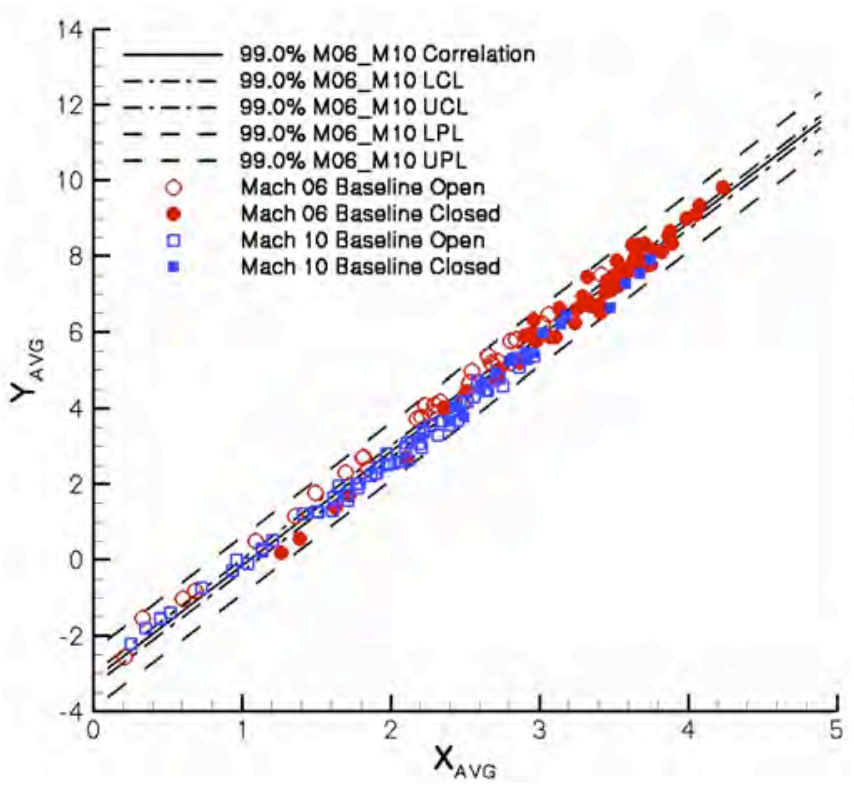

a) Cavity floor correlation.

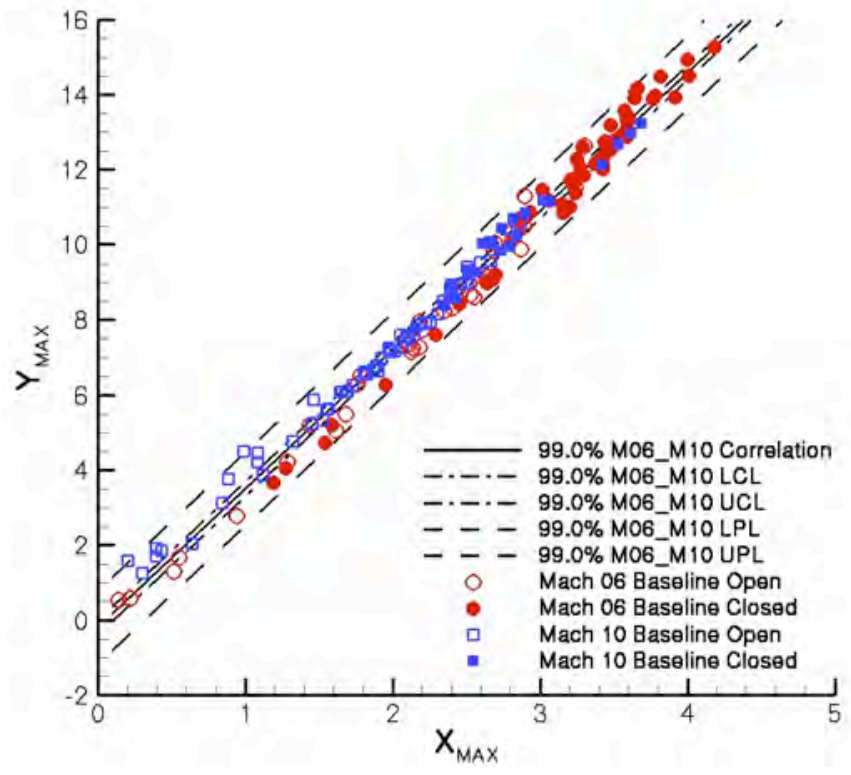

b) Cavity endwall maximum correlation.

Figure 16.- Comparison of baseline Mach 6 and Mach 10 correlation parameters with $99 \%$ combined Mach 6/Mach 10 correlation.

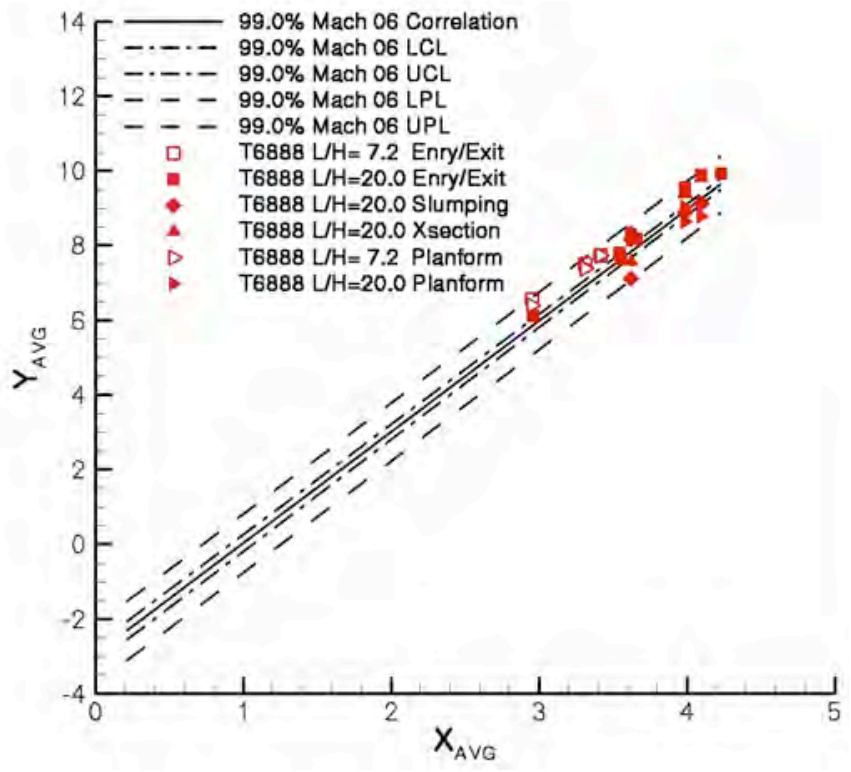

a) Cavity floor correlation.

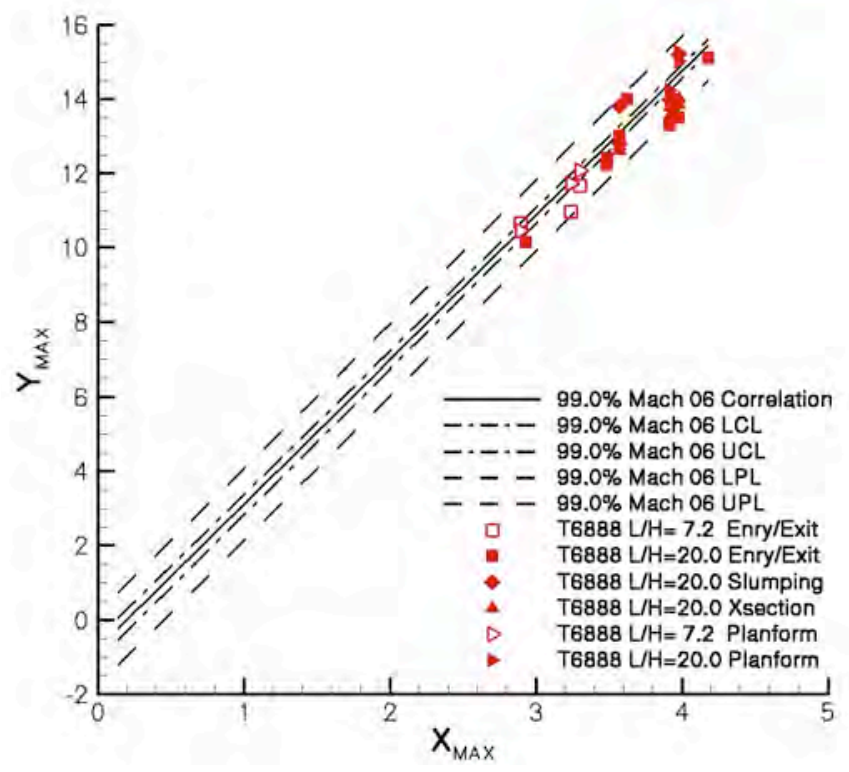

b) Cavity endwall maximum correlation.

Figure 17. Comparison of non-baseline Mach 6 correlation parameters with 99\% Mach 6 correlation. 


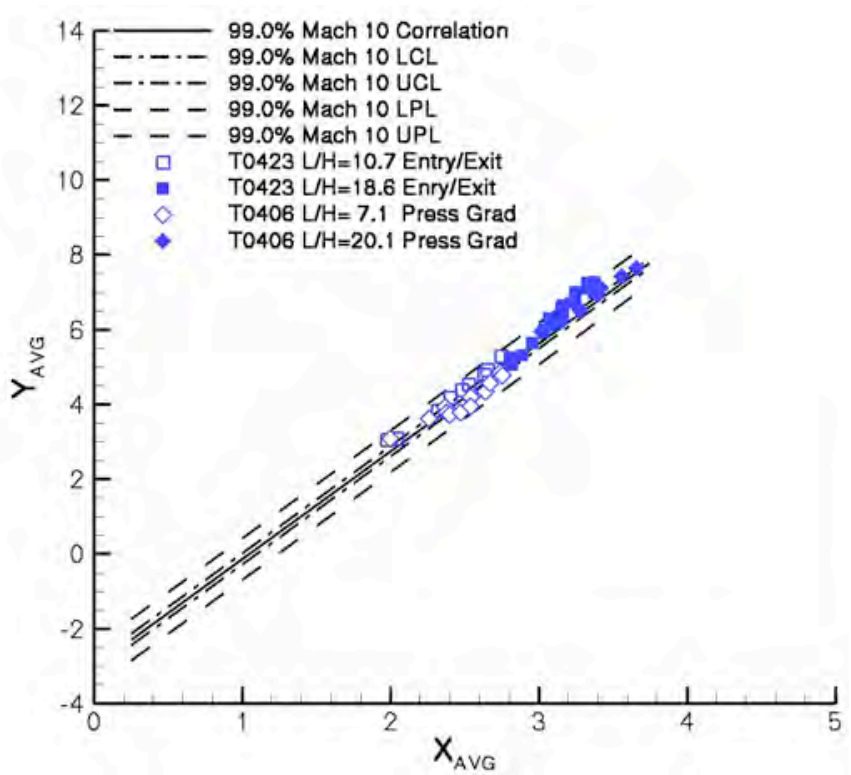

a) Cavity floor correlation.

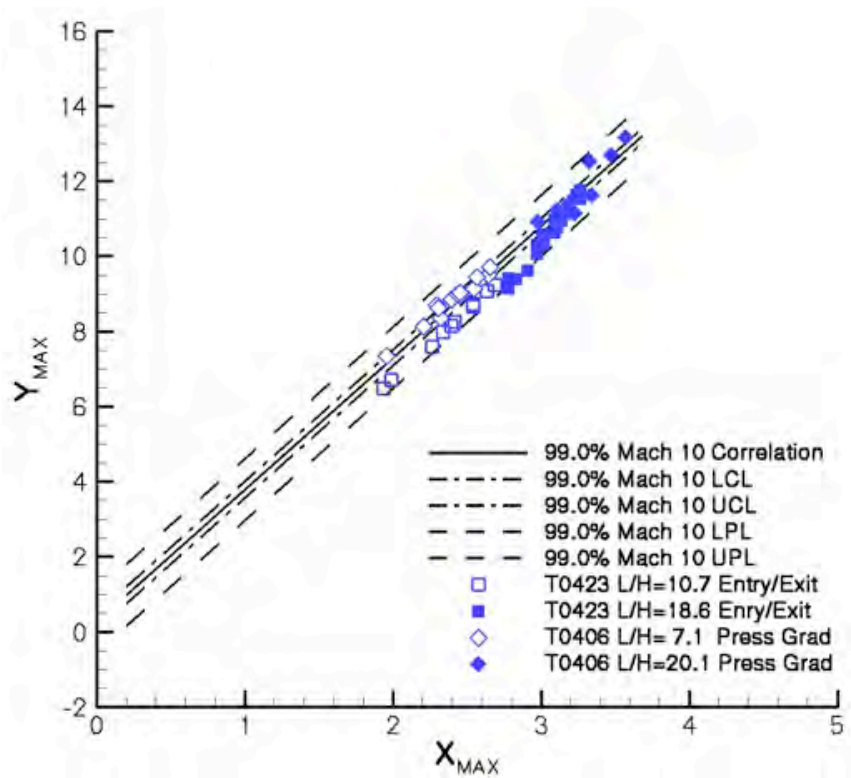

b) Cavity endwall maximum correlation.

Figure 18. Comparison of non-baseline Mach 10 correlation parameters with $99 \%$ Mach 10 correlation.

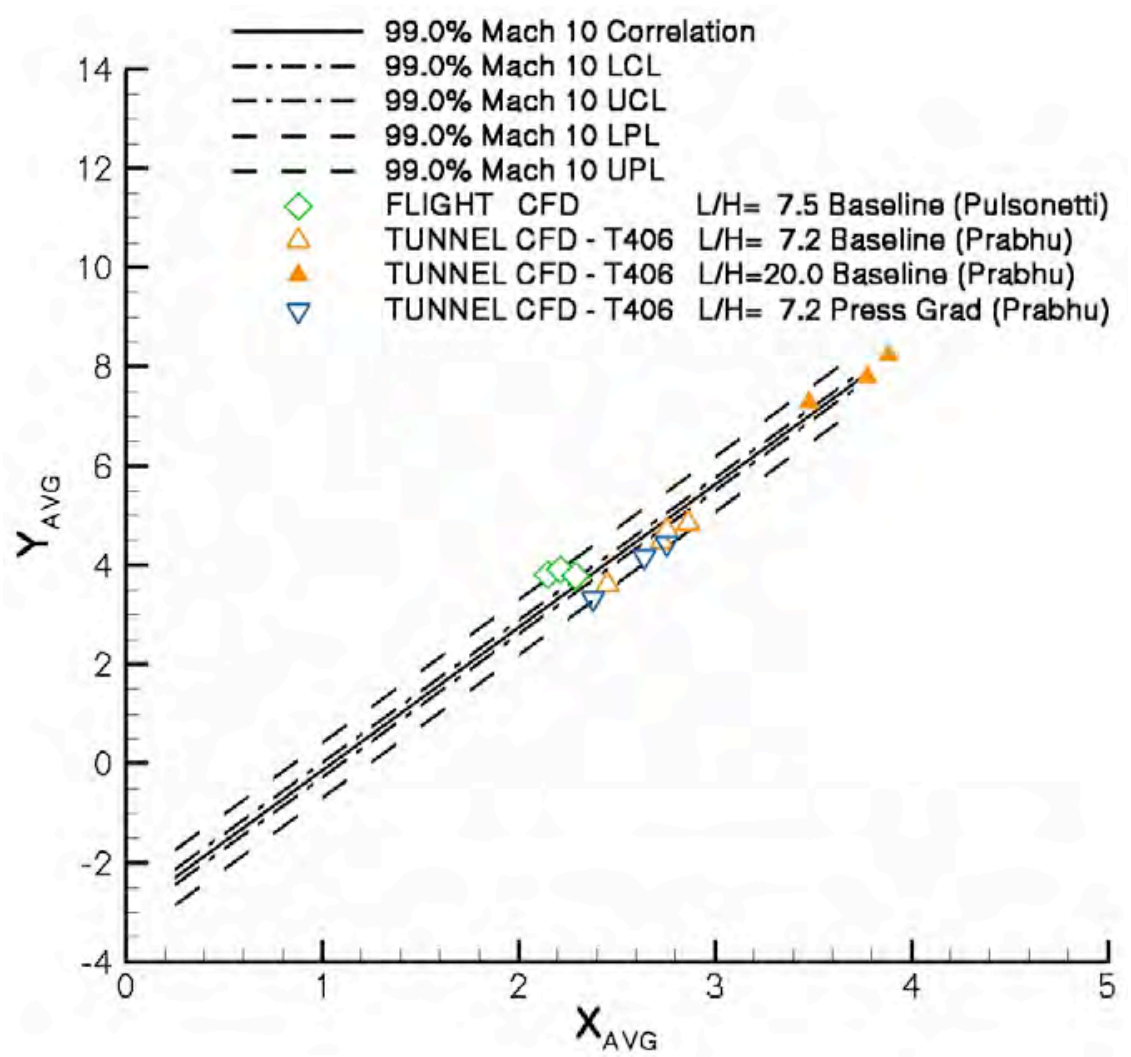

Figure 19. Comparison of computational cavity simulations with $99 \%$ Mach 10 floor correlation curves. 


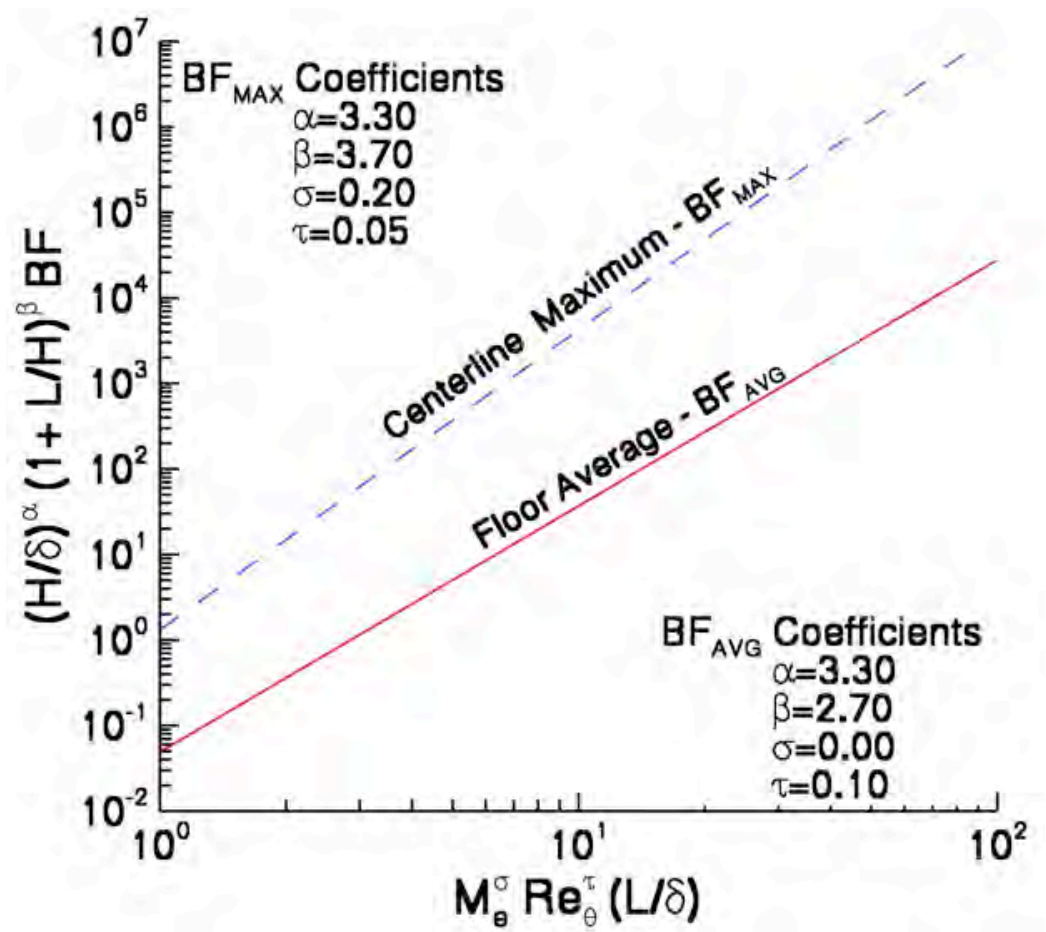

Figure 20. The $B F_{A V G}$ and $B F_{M A X}$ Correlation Curves derived from the Mach 10 Tunnel data set.

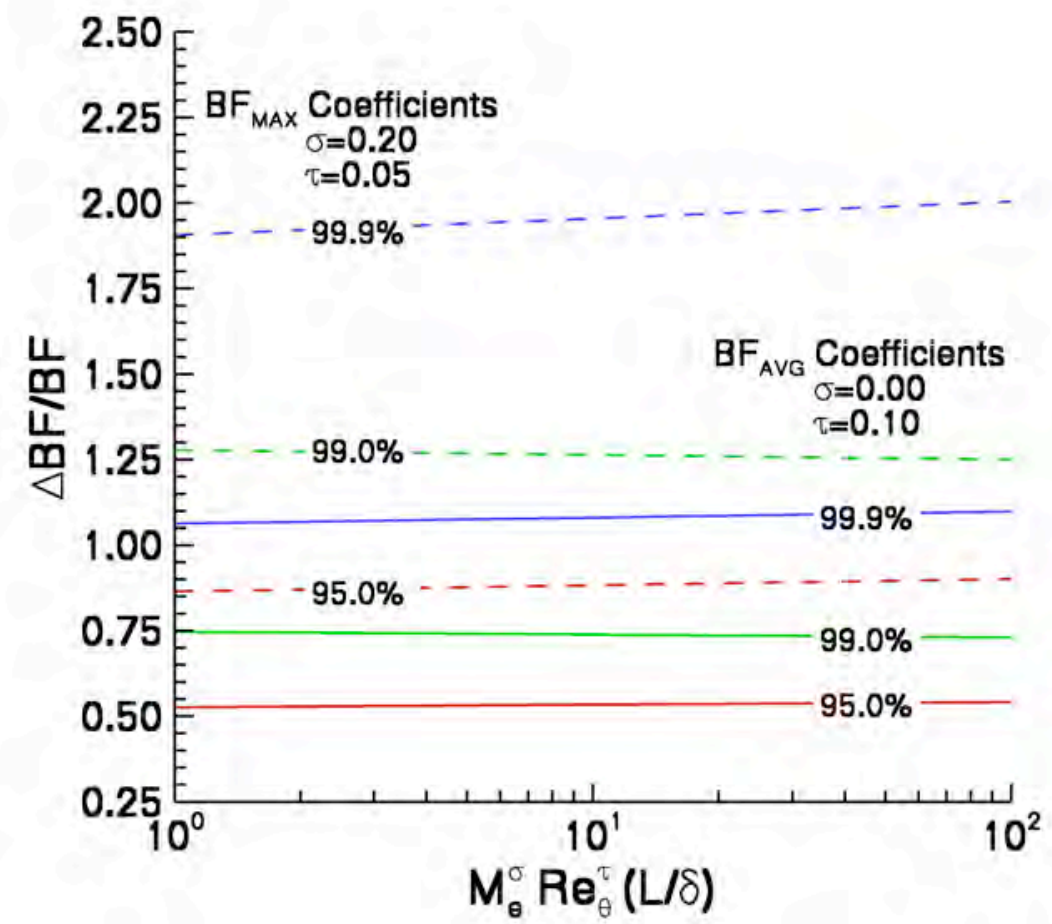

Figure 21. The $B F_{A V G}$ and $B F_{M A X}$ Uncertainty Prediction Curves derived from the Mach 10 Tunnel data set. 


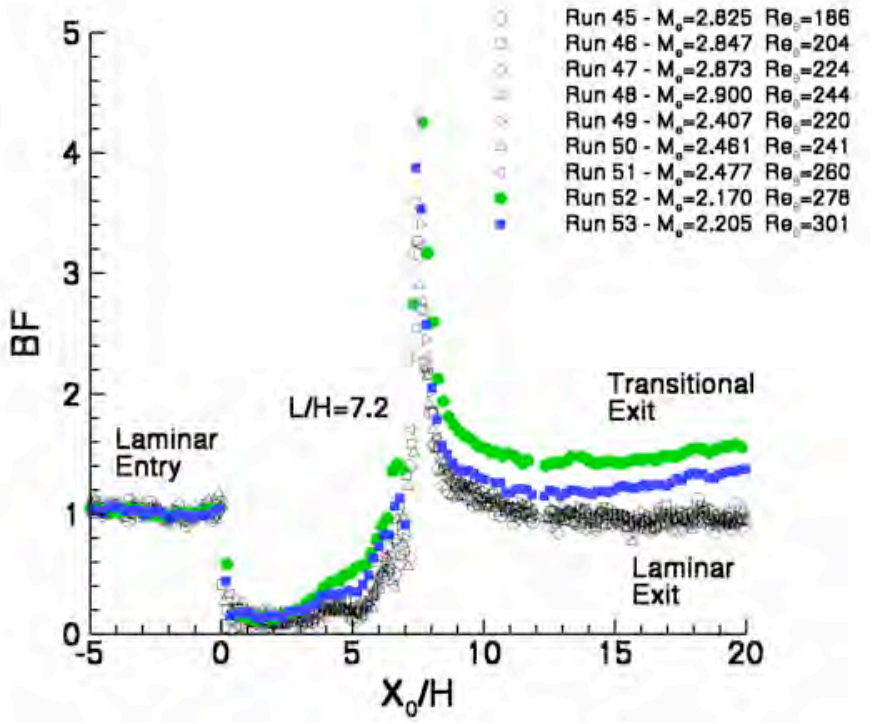

a) $\mathrm{L} / \mathrm{H}=7.2$.

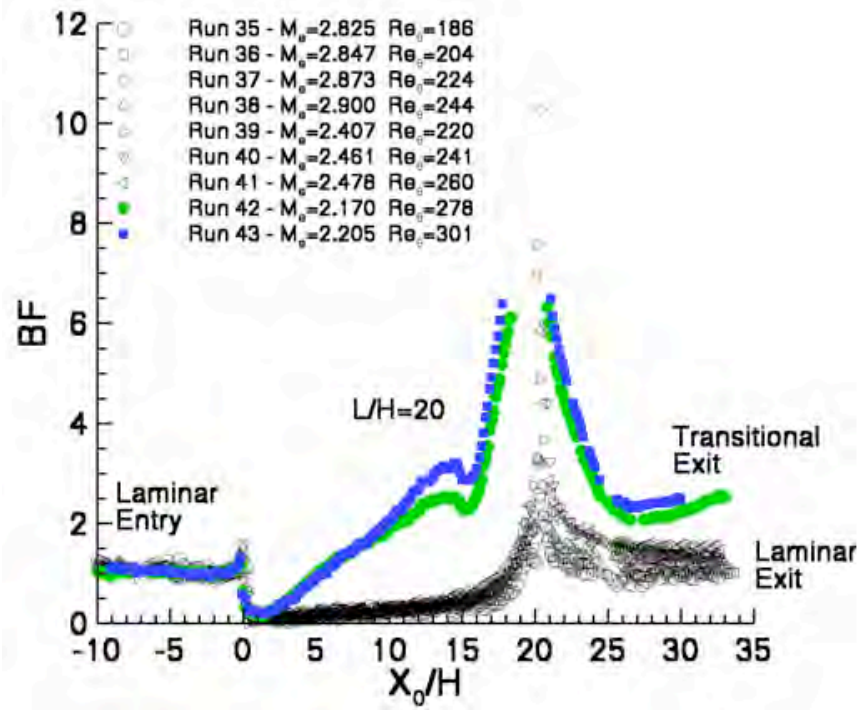

b) $\mathrm{L} / \mathrm{H}=20$.

Figure 22. Representative centerline Bump Factor distributions from Mach 10 Test 406.

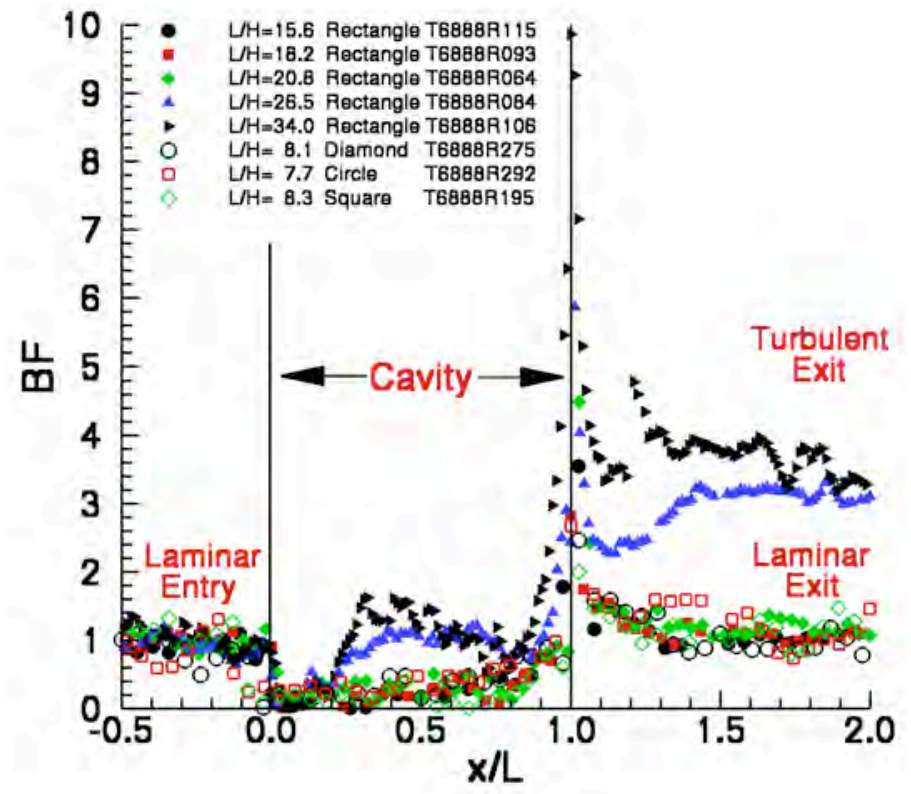

Figure 23. Centerline Bump Factor distributions from Mach 6 Test 6888 demonstrating planform insensitivity. 


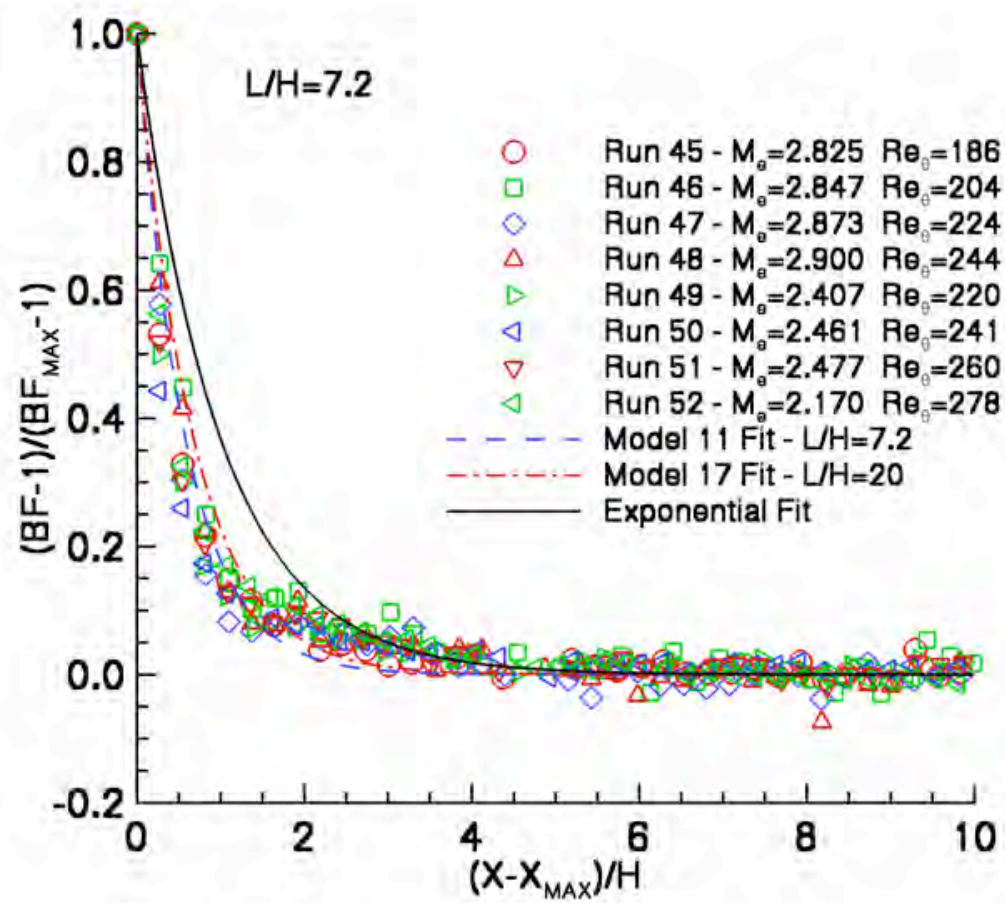

Figure 24. Cavity heating disturbance decay rate for Test $406 \mathrm{Model} 11(\mathrm{~L} / \mathrm{H}=7.2)$.

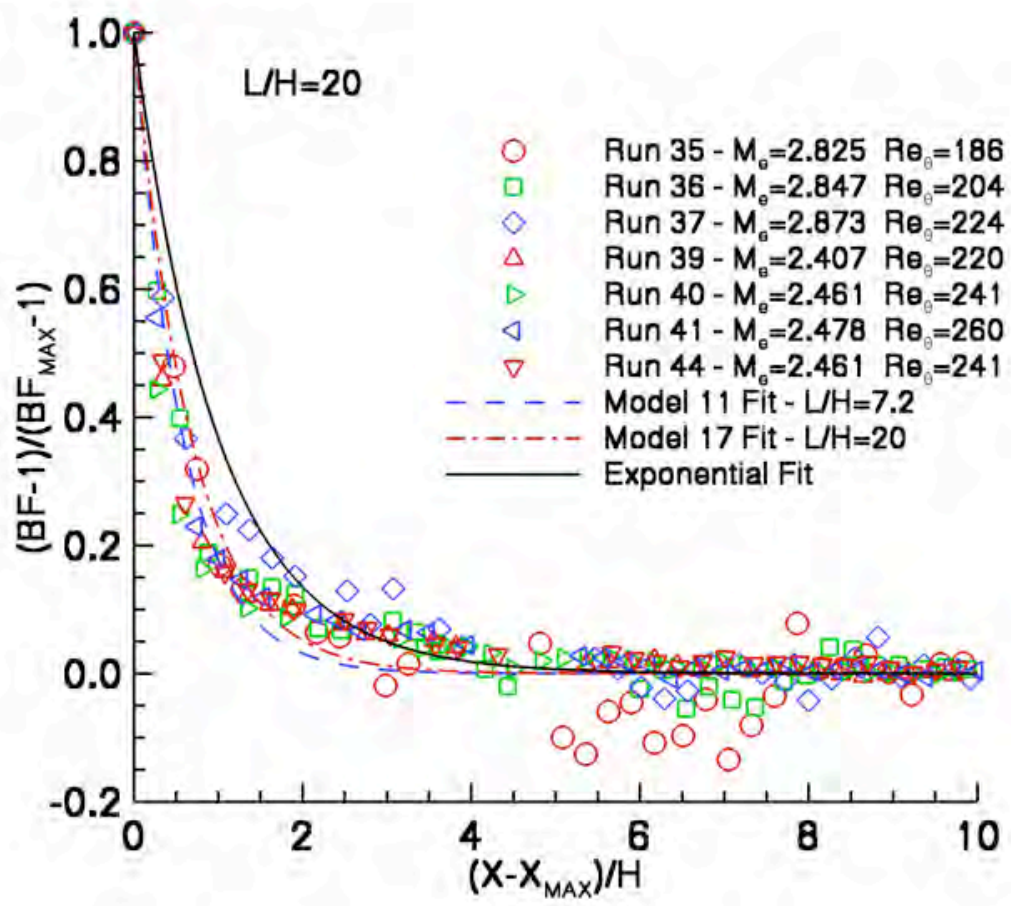

Figure 25. Cavity heating disturbance decay rate for Test $406 \operatorname{Model} 17$ (L/H=20). 